\title{
Investigating face veneer check development in decorative plywood panels: the impact of four common manufacturing factors
}

\author{
Michael Burnard ${ }^{1,2}\left(\mathbb{D} \cdot\right.$ Scott Leavengood ${ }^{3}(D) \cdot$ Lech Muszyński $^{3} \cdot$ Lisa Ganio $^{4}$
}

Received: 13 December 2018 / Published online: 13 September 2019

(c) The Author(s) 2019

\begin{abstract}
An optical method based on digital image correlation was used to investigate the impact of four decorative plywood manufacturing factors (core type, veneer type, adhesive type and lathe check orientation) on face veneer checking. The four core types were: combination core, medium density fibreboard, particleboard, and veneer core. The four veneer types were: peeled $0.604 \mathrm{~mm}$, peeled $0.706 \mathrm{~mm}$, sliced $0.508 \mathrm{~mm}$, and sliced $0.564 \mathrm{~mm}$. Both loose-side out and tight-side out lathe check orientations were used. The adhesive systems were urea-formaldehyde, polyvinyl acetate, and soy-protein based. 96 treatment combinations with 8 replicates were tested. All specimens were exposed to harsh but realistic drying conditions (approximately $30^{\circ} \mathrm{C}$ and $26 \%$ relative humidity) for $4 \mathrm{~h}$ during inspection. Checks were detected on 428 out of a total of 765 specimens (56\%). The estimated mean check densities (area of checking per unit area) indicated some unfavourable factor combinations. All factors had some degree of interaction with one another and check development could not be attributed to a single factor examined in this study. The data were fit to a generalized linear mixed model based on Tweedie's compound Poisson distribution. Confidence intervals were calculated via bootstrapping. The check density estimates produced by this model can be used to cautiously guide manufacturers as they decide on panel components. The broader use of the model is to highlight the complexity of the problem and guide future research in this area.
\end{abstract}

\section{Introduction}

Decorative hardwood plywood panels are wood-based composites comprised of hardwood veneers bonded to centre layers (or "cores") which may be veneer, lumber, particleboard,

Michael Burnard

michael.burnard@iam.upr.si; mike.burnard@innorenew.eu

Scott Leavengood

scott.leavengood@oregonstate.edu

Lech Muszyński

lech.muszynski@oregonstate.edu

Lisa Ganio

lisa.ganio@oregonstate.edu

1 Andrej Marušič Institute, University of Primorska, Muzejski $\operatorname{trg}$ 2, 6000 Koper, Slovenia

2 InnoRenew CoE, Livade 6, 6310 Izola, Slovenia

3 Department of Wood Science and Engineering, College of Forestry, Oregon State University, 119 Richardson Hall, Corvallis, OR 97331, USA

4 Department of Forest Ecosystems and Society, College of Forestry, Oregon State University, 321 Richardson Hall, Corvallis, OR 97331, USA medium density fibreboard (MDF), hardboard, or a combination of these materials (Stark et al. 2010). They are commonly used in applications where quality appearance is desired, including cabinetry, furniture, fixtures, wall and ceiling panels. In uses where appearance is most critical, any defect in the face veneer can lead to complaints by the customer. For many years a common and costly customer complaint has been checking in the face veneer (Holcombe 1952; Cassens et al. 2003; Leavengood et al. 2011). No standard stipulates the minimum wood-tissue separation to qualify as a check, and no study has assessed end-user views on acceptable levels of checking in finished panel products. Therefore, based on physical examination of panels that produced customer complaints, checks in this study were defined as separations of the wood tissue along the fibre direction, greater than $0.2 \mathrm{~mm}$ across (i.e. in width) and longer than $1 \mathrm{~mm}$ (Burnard 2012). When the surface is exposed to a low humidity environment, moisture gradients between the face veneer and core materials develop; variable shrinkage rates between the face veneer and the core material generate drying stresses, which are the principal cause of checking in hardwood plywood products (Gilmore and Hanover 1990; Forbes 1997; Schramm 2003; Cassens et al. 
2003; Christiansen and Knaebe 2004; Leavengood et al. 2011). While decorative surfaces may only occasionally be exposed to drying conditions severe enough to induce checking, it takes only one such event to generate an irreversible damage resulting in an expensive claim.

Checking in decorative hardwood plywood veneers is commonly believed to depend on specific panel construction and many manufacturing options such as adhesive properties and choice, core materials, component moisture content at time of pressing, veneer cutting and drying methods, etc. (Holcombe 1952; Feihl and Godin 1970; Gilmore and Hanover 1990; Forbes 1997; Cassens et al. 2003; Schramm 2003; Christiansen and Knaebe 2004; Leavengood et al. 2011).

\subsection{Panel construction and manufacturing options}

The selection of specific wood species and finishes for face veneers is subject to consumer choices and fashion. Sugar maple (Acer saccharum, a hard maple), the species examined in this study, has been a common choice for many years and accounts for approximately $43 \%$ of North American unfinished materials and $70 \%$ of prefinished materials (Schramm 2003; HPVA 2011, 2018). Common core materials are medium density fibreboard (MDF), particleboard (PB), veneer $(\mathrm{V})$, and combination core (typically softwood veneer with a thin layer of MDF on the front and back). Common adhesive systems used to bond the decorative veneers on the core include urea formaldehyde based adhesives (UF), soybased adhesives (Soy), and polyvinyl acetate based adhesives (PVA). There are other manufacturing options such as $\log$ source region and conditioning treatment, veneer cutting method, veneer thickness and grain angle, moisture content and lathe check orientation of the veneer, pressing time and temperature, specific adhesive formulations, panel storage and handling, surface coatings, and others. Previous studies and reports conclude or suggest the factors discussed in the following subsections have significant impact on check formation.

Veneer properties and lathe-check orientation Veneer properties including cutting method, (e.g., sliced or peeled), lathe check orientation, veneer thickness, moisture content at time of pressing, and thickness are all believed to play a role in check development of decorative hardwood panels (Forbes 1997; Schramm 2003; Christiansen and Knaebe 2004). Even the wide variability of properties within veneers of the same type due to features of wood (e.g., grain angle, reaction wood) may contribute to differential checking severity.

Cutting method affects checking because rotary peeling (also called rotary cutting) tends to expose mostly the tangential plane in wood, while slicing may produce veneers with radial faces as well. With the tangential shrinkage rates approximately double the radial shrinkage rates $(9.9 \%$ compared to $4.9 \%$ in sugar maple; Glass and Zelinka 2010), faces made of peeled veneers may experience more severe stress built up during exposure to drying conditions than sliced veneers.

One of the key, and much discussed, options in panel construction is whether the veneer is attached to the panel with its tight- or loose-side out (Cassens et al. 2003; Leavengood et al. 2011). Loose-side refers to the side of the veneer that was in contact with the knife blade during the slicing or peeling process, the opposite side is the tight-side. For many years it has been common practice to place the veneer looseside down to limit check development (Holcombe 1952; Batey 1955; Feihl and Godin 1970; Cassens et al. 2003; Schramm 2003; Christiansen and Knaebe 2004). However, limited evidence indicates that orienting face veneers loose-side out reduced the propensity for development of new checks in panels with oak veneers (Cassens et al. 2003), while conflicting conclusions have been reported on similar effect in panels with maple veneer (compare Leavengood et al. 2011; Cassens et al. 2003). Lathe-check orientation is thought to be important because more pre-existing cracks are present on the loose-side. The severity of pre-existing cracks and the causes for them have been examined by many researchers (recently, Buchelt et al. 2018; Rohumaa et al. 2018). While research examining the causes and severity of pre-existing cracks exist, their association with the development of surfacing checking in products is limited to lathe-check orientation. No rapid method of characterising pre-existing cracks in large surface areas is known to exist.

Veneer thickness also contributes to check development: checks formed in thicker veneers tend to be fewer but are often wider and more readily apparent than shallow and narrower checks in thinner veneers (Christiansen and Knaebe 2004).

Controlling the moisture content of the face and back veneers at the time of pressing is thought to be one effective method of mitigating check development (Christiansen and Knaebe 2004; Schramm 2003; Cassens et al. 2003). Cassens et al. (2003) recommend conditioning the veneer and core components to the average equilibrium moisture content at the service location to reduce excessive swelling or shrinking after installation. Wilson (2018) found no relationship between checking and the difference between core MC and surface veneer $\mathrm{MC}$ at the time of pressing.

Adhesive choice is commonly believed to affect check development (Gilmore and Hanover 1990; Forbes 1997), however there have been very few studies documenting or explaining this effect. It is certain however, that adhesives applied as water solutions contribute moisture to veneers and to the core surfaces. Overall, more checks have been observed in panels constructed with UF adhesive compared to those using PVA (Tremblay and Bouffard 2012). Cassens et al. (2003) found strong evidence that adhesive choice was 
part of multiple two-way interactions that influenced check development. Of the 16 treatment combinations examined, the one that checked the most was maple veneered panels bonded with PVA, with the loose-side of the veneer facing out, veneer $\mathrm{MC}$ at the time of pressing at $12 \%$ and a $10 \mathrm{~min}$ assembly. A significant 4-way interaction was also reported, increasing the difficulty of isolating any single factor or a simple combination of factors as the cause (Cassens et al. 2003).

Core materials are typically mentioned in best practice manuals as a factor contributing to the surface checking effect, along with other components, attributes or panel construction methods (e.g., the moisture content of the veneer, or the adhesive used in combination with the panel type, balanced construction). Little has been reported regarding the performance of specific core types, except for a study by Tremblay and Bouffard (2012), who examined particleboard, veneer, and MDF cores and concluded that panels with veneer cores were more prone to checking than those with particleboard and MDF cores.

This study is motivated as much by the persistent pressure from manufacturers for a comprehensive solution to the problem of check formation, as by the challenge the complexity of this problem and the apparent contradictions between previous studies have been posing to the research community for so long. The complex interactions reported by Cassens et al. (2003) mean that the problem may not be removed by altering individual factors. Another important conclusion from previous studies is that the problem cannot be properly resolved by analysing a small selection of the many variables that may influence check development at a time. Most of the methods used in previous studies may not be well positioned to process large number of specimens necessary to address multiple variables at a time. They may also limit accurate detection and resolution of differences in check development indicators and patterns between panels. For example, measuring checks at specific time intervals, rather than as they form, is likely to lead to significantly underestimated checking measurements given that checks in face veneer may close as the core material equilibrates to the ambient conditions.

Recently, Burnard et al. (2018) developed a new automated optical method for detection and measurement of checks based on check detection concept proposed by Kang et al. (2006). This method was based on the digital image correlation principle, which allowed identification of checks as small as $0.2 \mathrm{~mm}$ wide and $1 \mathrm{~mm}$ long. Continuous measurement allowed reliable check counts, and measurement of check dimensions as they develop during exposure to drying conditions. Check density, the summed area of check per panel area, was proposed as an indicator of check severity. The method was validated in exposure tests conducted in harsh but realistic conditions, to increase the likelihood of checking and reduce the test duration to $4 \mathrm{~h}$. The test setup allowed near simultaneous monitoring of check development in up to 48 panel specimens sized $300 \mathrm{~mm} \times 300 \mathrm{~mm}$. The efficiency of the method allows studies to examine a large number of treatments and replicates and overcomes most of the limitations discussed in relation to earlier methods.

\subsection{Objectives}

The objective of this study was to use the check detection and measurement methodology developed by Burnard et al. (2018) to determine the effect of four factors related to manufacturing of the decorative hardwood plywood commonly believed to affect checking: veneer characteristics, lathe orientation, core material and adhesive type, as well as combinations of these factors in maple plywood.

\section{Materials and methods}

The investigation was performed using 8 replicates of laboratory-fabricated test specimens of each of the 96 combinations of the 4 factors selected for this study. The test procedure, including the panel construction, preparation for testing, exposure to rapid drying conditions, data collection and analysis, followed the methodology developed earlier by Burnard et al. (2018). Factors and levels of factors thought to contribute significantly to check development in maple veneer plywood panels were identified based on literature review and by consultation with industry advisors. Statistical analysis of the data (e.g., checking severity) followed utilising robust methods appropriate for the observed data and experimental design.

\subsection{Experimental design}

The test variables included: (1) veneer cutting method and thickness; (2) lathe check orientation; (3) core material; and (4) adhesive type. Specific values for each of these variables were determined based on a survey conducted among decorative panel producers in the U.S. producing panels with sugar maple veneer faces (Burnard 2012):

1. In practice, peeled and sliced veneers are produced in different thicknesses. Oregon hardwood plywood manufacturers use peeled veneer in thicknesses between 0.604 and $0.706 \mathrm{~mm}$ (in US industry these are, 1/32" and $1 / 36^{\prime \prime}$ ), and sliced veneer between $0.508 \mathrm{~mm}$ and $0.564 \mathrm{~mm}$ (in US industry these are, $1 / 45^{\prime \prime}$ and 1/50"; Burnard 2012). Therefore, in this study, veneer cutting method and thickness (the factor further referred to as "veneer") are treated as a single factor with 4 values: (a) peeled $0.604 \mathrm{~mm}$; (b) peeled $0.706 \mathrm{~mm}$; (c) sliced 
$0.508 \mathrm{~mm}$; and (d) sliced $0.564 \mathrm{~mm}$ (thickness values are nominal). Sliced veneers were slip-matched, rather than book-matched, to ensure lathe-check orientations were the same for all spliced components.

2. Two lathe check orientations were used: (a) tight-side out and (b) loose-side out. About half of the veneers had their tight- and loose-side labelled by the companies donating the material. The orientation of the unlabelled veneers was determined by the research team in a two-step procedure where two researchers physically inspected each sheet, identified the tight and loose sides, then compared results (Burnard, 2012).

3. Four core materials most commonly used by hardwood plywood manufacturers were tested: (a) Veneer core (VC); (b) MDF (medium density fibreboard); (c) "combination core" (CC): plywood with a combination of veneer core and thin layers of MDF adjacent to the decorative face veneer on both sides; and (d) particleboard (PB).

4. Three types of adhesives most commonly used by hardwood plywood manufacturers were investigated: (a) soybased (S); (b) urea formaldehyde adhesive (UF); and (c) polyvinyl acetate (PVA) adhesive.

The manufacturing variables (factors) and their specific values (levels) examined in this study are summarised in Table 1 . The resulting test matrix included 96 different manufacturing combinations (or treatments) with 8 replicates per treatment (a total of 768 test panels).

The experimental design in this study was a randomized block split-plot factorial design. Split-plots are generalisations of the factorial design when a factor cannot be entirely randomised. Blocking is used to help account for a known and controllable source of variation, such as any differences that may occur between panel manufacturing runs. In this study, one replication was produced per day so the production day constituted the blocking factor. Only one adhesive could be used at a time because of limitations to the stability of the adhesive at room temperature (i.e., its pot life), the availability of a single glue spreader in the laboratory, mixing, and clean-up times. Therefore, all treatments using a single adhesive type were made consecutively within each block and adhesive was treated as a split-plot factor in the analysis. Replications of the remaining factors (veneer type and thickness, veneer orientation, and core type) were randomly assigned within each replication of the adhesive. The number of observations per block and the number of levels for different combinations of the factors are presented in Table 2.
Table 1 Factors and levels of manufacturing variables

\begin{tabular}{lll}
\hline Factors & No. of levels & Levels \\
\hline $\begin{array}{l}\text { Veneer cutting method } \\
\text { and thickness (veneer) }\end{array}$ & 4 & Peeled, 0.706 mm \\
& & Peeled, $0.604 \mathrm{~mm}$ \\
& Sliced, 0.564 mm \\
& & Sliced, 0.508 mm \\
Veneer orientation & 2 & Tight-side out (TSO) \\
& & Loose-side out (LSO) \\
Core & 4 & Veneer (V) \\
& & Medium density fibreboard \\
& & (MDF) \\
& & Combination core (CC) \\
& & Particleboard (PB) \\
Adhesive & 3 & Soy-based (Soy) \\
& & Urea Formaldehyde (UF) \\
& Polyvinyl Acetate (PVA) \\
\hline
\end{tabular}

*These thicknesses correspond to commonly produced thickness in the US, which are customarily measured in inches, (e.g. $0.706 \mathrm{~mm}=1 / 36^{\prime \prime}$ )

\subsection{Manufacturing and conditioning panels}

Sample specimens were prepared from pre-cut $300 \mathrm{~mm} \times$ $300 \mathrm{~mm}$ cores and veneer sheets donated by cooperating companies, resulting in panels of the same size. Materials were conditioned at ambient lab environment at a mean temperature of $21.4 \pm 0.6{ }^{\circ} \mathrm{C}$ and mean relative humidity $31.3 \pm 5.9 \%$ (solid wood EMC between 5.4 and $7.3 \%$ ) for at least 7 days before being assembled and pressed.

The PVA adhesive was received pre-mixed by the manufacturer. The pot life was sufficient to last throughout the entire production phase. The UF adhesive was mixed in the lab according to manufacturer instructions before each production cycle. The soy-based adhesive was received premixed by the company and delivered in small batches, which were refrigerated between production cycles. Per manufacturers' recommendations all adhesives were applied with a target spread rate of $177 \mathrm{~g} / \mathrm{m}^{2}$ (15.9 g per glue line) using a laboratory-scale adhesive spreader. All test panel cores were weighed before and after applying the adhesive. The average measured spread rate for all panels was confirmed at $15.9 \pm 1.3 \mathrm{~g}$ per glue line.

Manufacturing procedures Specimen production order was randomized ahead of production which included consideration for the adhesive split-plot factor. The adhesive for the production day was prepared and applied to the spreader, then all specimens using that adhesive within the current block were produced pulling veneers and cores at random from the available stock.

Due to damaged sliced veneers, only 7 out of 8 planned replicates of $0.508 \mathrm{~mm}$ sliced veneer with loose-side out veneer orientation, particleboard core, and UF adhesive, and 
Table 2 Factor combinations, treatments, and observations

\begin{tabular}{lcc}
\hline Factors and factor combinations & $\begin{array}{l}\text { No. of levels per factor or } \\
\text { combination of factors }\end{array}$ & $\begin{array}{l}\text { No. of observations for each } \\
\text { combination in one block }\end{array}$ \\
\hline Veneer & 4 & 24 \\
Veneer orientation & 2 & 48 \\
Core type & 4 & 24 \\
Adhesive & 3 & $3^{\mathrm{a}}$ \\
Veneer $\times$ core type & 16 & 6 \\
Veneer $\times$ adhesive & 12 & 8 \\
Veneer $\times$ veneer orientation & 8 & 12 \\
Core $\times$ adhesive & 12 & 8 \\
Core $\times$ veneer orientation & 8 & 12 \\
Adhesive $\times$ veneer orientation & 6 & 16 \\
Veneer $\times$ core $\times$ adhesive & 48 & 2 \\
Veneer $\times$ core $\times$ veneer orientation & 32 & 3 \\
Core $\times$ adhesive $\times$ veneer orientation & 24 & 4 \\
Veneer $\times$ core $\times$ adhesive $\times$ veneer orientation & 96 & 1 \\
\hline
\end{tabular}

${ }^{\text {a }}$ The average of checking values for all 32 panels made with a single adhesive type constituted an observation
7 replicates of $0.508 \mathrm{~mm}$ sliced veneer, tight-side out, MDF, UF adhesive were produced. As a result, 766 test panels were produced rather than the target of 768 .

All panels were assembled with only the face veneer (no back veneer was applied) to speed up the assembly. No significant buckling or bending was observed at pressing time or prior to exposure, however this was not measured.

In the sample preparation process, face veneers on veneer cores were inadvertently applied with the grain direction oriented parallel to the grain direction in the core faces. While some commercial panels are assembled this way, it is rare, and this is thought to contribute to the severity of checking (Tremblay and Bouffard 2012).

Pressing procedure and conditions followed manufacturer recommendations: all panels were pre-pressed at room temperature for $5 \mathrm{~min}$ at $0.930 \mathrm{MPa}$ in a CP SPX 55T ECN Press 1851 , and then hot-pressed for $2 \mathrm{~min}$ at $0.930 \mathrm{MPa}$ with the face veneer oriented toward the top platen set to $113^{\circ} \mathrm{C}$ in a Clifton Hydraulic Press 1500.

After pressing, sample panels were cooled and stored at conditions of $20{ }^{\circ} \mathrm{C}$ and $65 \%$ relative humidity (i.e., solid wood equilibrium moisture content of approximately $12.0 \%$ ) for a minimum of $72 \mathrm{~h}$.

Twenty-four hours before testing, a random speckle pattern (a sparse spray of white and black acrylic matte paint) was applied to all veneered surfaces to enhance optical measurement of surface strain development (Burnard et al. 2018). Samples were then moved to a conditioning chamber set to $30{ }^{\circ} \mathrm{C}$ and $90 \%$ relative humidity (solid wood EMC of approximately $20 \%$ ) for $24 \mathrm{~h}$.

\subsection{Measuring check severity}

Check severity was measured using the optical method developed by Burnard et al. (2018). In this method, small surface checks were detected and measured by means of an optical full-field strain analysis based on the digital image correlation (DIC) principle. Kang et al. (2006, 2011) demonstrated that even very small checks may be detected and monitored as apparent local peak in magnitude of strains measured perpendicular to the surface grain.

Tests were performed on groups of 32 panels simultaneously. Test panels were exposed to relatively harsh but realistic drying conditions (approximately $30{ }^{\circ} \mathrm{C}$ and $26 \% \mathrm{RH}$ which for solid wood is equivalent to EMC of $5.39 \pm 0.21 \%$ ) maintained for $240 \mathrm{~min}$. The final group consisted of 30 specimens. During the exposure, an automated image acquisition system with a digital camera (5 megapixel monochrome Grasshoper 2) mounted on an $8 \mathrm{~m}$ horizontal linear positioning track system allowed sequential examination of all test specimens in 10 min intervals. Finally, automated identification of checks allowed batch processing of the data collected during the exposure tests. The system used a custom image capture and track control system, as well as a custom check detection and measurement system. The check detection and measurement system used displacement and strain measurements exported from ARAMIS 5.4.3 by GOM, mbH (2004). A detailed description of the system is presented in Burnard et al. (2018).

The system was calibrated to detect checks at least $0.2 \mathrm{~mm}$ wide, with a precision of $\pm 0.03 \mathrm{~mm}$ (Burnard et al. 
2018). The check metrics returned by the system included check count, dimensions (width and length) and position of all detected checks as they developed over the exposure time.

In order to allow quick quantitative comparison of checking severity observed on sample surfaces of varying dimensions, check density (CD) was calculated as a ratio of the total area of all checks detected on a panel $\left(\mathrm{A}_{\mathrm{ck}}\right)$ expressed in square millimetres to the examined area of interest $\left(\mathrm{A}_{\mathrm{ROI}}\right.$, Eq. 1) expressed in square meters (Burnard et al. 2018).

$C D=\frac{A_{c k}}{A_{R O I}}\left[\frac{m m^{2}}{m^{2}}\right]$

In this study, as in the system validation study (Burnard et al. 2018), CD was observed over a 4-h exposure in order to capture the check development dynamics in panels. In the validation study, the gradual accumulation of checks with increasing moisture gradient through the thickness of the panel was reflected as gradual build-up of CD until a peak, beyond which the moisture begins to equilibrate and the CD decreased as the checks gradually closed. Since the rate of check formation was shown to be different for individual panels and between the test layups, comparing the CDs for all test samples at some arbitrary time snapshot would not yield meaningful assessment. Instead, the peak $C D$ values observed in panels over the exposure times were compared and analysed.

\subsection{Statistical analysis}

A substantial number of panels survived the exposure tests without detectable checks $(>0.2 \mathrm{~mm}$ in width and longer than $1 \mathrm{~mm}$ ) while the distribution of the observed, non-zero check densities was heavily right-skewed. Both conditions violated the assumption of a normal distribution with homogeneity of variance and therefore common ANOVA methods could not be used.

The observed data met the assumptions of the Tweedie compound Poisson distribution (Zhang 2013), which allowed us to use a linear mixed model. In this model, the number of observed checks, $X$, is a Poisson distributed random variable with mean $\lambda$ (Eq. 2):

$X \sim \operatorname{Pois}(\lambda) ; X=0,1,2,3,4, \ldots$

and the area of an individual check, $Y_{i}$, is a Gamma random variable with mean $\alpha$ and variance $\alpha \beta^{2}$ (Eq. 3):

$Y_{i} \sim G a(\alpha \beta)$, for $Y>0$

$\mathrm{A}_{\mathrm{ck}}$, the total area of observed checks in a single panel at a specific stage, is defined as:

$A_{c k}=\sum_{i=1}^{X} Y_{i}$
So that the check density, $\mathrm{CD}$, is as defined in Eq. (1). In this case, the $\mathrm{CD}$ reported is the maximum observed within the test period.

A generalized linear mixed model based on the Tweedie compound Poisson distribution was fitted to the observed data using a logarithm link function for the mean $\mathrm{CD}$. The linear model included fixed effects for the factors (veneer type and thickness, lathe check orientation, core, and adhesive types) and all 2, 3, and 4-way interactions. In addition, assessed models included random effects of day (block variation) and adhesive*day (whole plot variation).

Estimation of standard errors, and functions of standard errors such as statistical hypothesis tests and uncertainty measures for this model are not well estimated (Zhang 2013). Instead analysis must be based on the ordered arrangement of estimated means for each combination of factors and their associated $95 \%$ confidence intervals (CIs).

Furthermore, the estimation theory of generalized linear mixed models (such as the Tweedie compound Poisson linear mixed model used in this study) for distributions other than the normal distribution, is not completely mathematically tractable. In particular, it is not known how the estimation of the random effects should be incorporated into the standard errors of the estimated means, making estimates of standard normal confidence intervals unreliable. To address this issue, the bootstrap method was employed to extract point estimates of the mean of each treatment and their associated confidence intervals, and to confirm model parameters.

The bootstrap method is a non-parametric computational method used in place of theoretical approaches that rely on strong distributional assumptions to estimate precision and confidence intervals from observed experimental data (Efron and Tibshirani 1986). The bootstrap method proceeds as follows: resample the observed data with replacement, recalculate the statistic(s) of interest, record, and repeat $n$ times. From these results, accurate confidence intervals can be calculated by various methods, including several nonparametric methods which do not rely on distributional assumptions about the data (Efron 1984; Efron and Tibshirani 1986; DiCiccio and Efron 1996; Davidson and Kuonen 2003; Haukoos and Lewis 2005).

In the current implementation, the model parameters, means, and their confidence intervals were calculated based on 10,000 bootstrap repititions. In addition to estimates for each observation, estimates of the index and dispersion parameters of the fitted gamma distribution, as well as the variance of the whole plot and residual random effect were recorded. The blocking random effect was not included in the bootstrapped Tweedie compound Poisson model, as it was considered to be an insignificantly small source of variation in the model and prevented resampling for the bootstrap. 
Following this procedure, confidence intervals were calculated using bias-corrected accelerated confidence intervals $\left(\mathrm{BC}_{\mathrm{a}}\right.$, DiCiccio and Efron 1996).

Statistical analysis was performed using R (version 3.3.3; R Core Team 2017), in RStudio (version 1.0.136; RStudio, Inc. 2016) with the cplm package for fitting the Tweedie compound Poisson distribution (version 0.7.5; Zhang 2013, 2017). Bootstrapping was implemented and $\mathrm{BC}_{\mathrm{a}}$ confidence intervals were calculated using the boot $\mathrm{R}$ package (version 1.3.18; Davison and Hinkley 1997; Canty and Ripley 2019). Plots were created with the ggplot 2 R package (version 2.2.1; Wickham 2009), the scales R package (version 0.4.1, Wickham 2016), and the gridExtra $\mathrm{R}$ package (Auguie 2016). Data cleaning and preparation utilised the tidyr and dplyr R packages (Wickham 2017; Wickham and Francois 2016). Documentation of the statistical analysis with the bootstrap script and the input and output data are available as supplemental material to this publication (Burnard and Ganio 2019).

\section{Results}

\subsection{General observations}

Of the 766 panels tested, detectable checks developed in 429. One panel was rejected from the data set because the suspiciously wide check regions determined by the system could not be corroborated with direct observation of the surface. It is likely that this error was caused by a local disturbance in the speckle pattern. The remaining 428 panels with detectable checks constituted $56 \%$ of the total 765 qualified panels. Panel checking status, that is the binary condition of having checked or not, was similar among the levels of each factor (Fig. 1, bars). Core type is the notable exception to this observation; checking occurred in $71 \%$ of panels (136 out of 192) with veneer core, in $60 \%$ of panels with combination cores, $49 \%$ in panels with MDF cores and $44 \%$ in panels with particleboard cores. However, the proportion of overall CD accounted for by each factor level varied significantly (Fig. 1, dots). For example, while $71 \%$ of veneer core panels checked, $47 \%$ of the total CD was accounted for by veneer core panels compared to $45 \%$ and $10 \%$ for particleboard, respectively. This may indicate some of the tested panel components are likely to contribute to check severity (increase CD).

Figures $2 \mathrm{a}$, b summarize observed peak check densities (CD). The CD histogram in Fig. 2 shows that the observed CDs were mostly within $100 \mathrm{~mm}^{2} / \mathrm{m}^{2}$. The distribution was heavily right skewed (Fig. 2a), with few severe cases between 3000 and $7200 \mathrm{~mm}^{2} / \mathrm{m}^{2}$ (between 2 and 13 checks detected). These distributions are much easier to examine on a natural logarithmic scale as in Fig. 2 b.

Check progression varied greatly over time even among replicated panels from the same treatment groups. In all cases where checking occurred, the maximum detected CD occurred after the 120th minute of the test period, and in many cases $\mathrm{CD}$ was observed to decrease following the peak. In $56 \%$ of all panels with detectable checks, the maximum CD occurred prior to the 240th, and final, minute of
Fig. 1 Panel checking state and observed share of total $\mathrm{CD}$ by factor and level. Bars are proportion of panels of a given factor level with observed checking. Points indicate the proportion of total observed $\mathrm{CD}$ accounted for by factor level (total of $100 \%$ per factor)
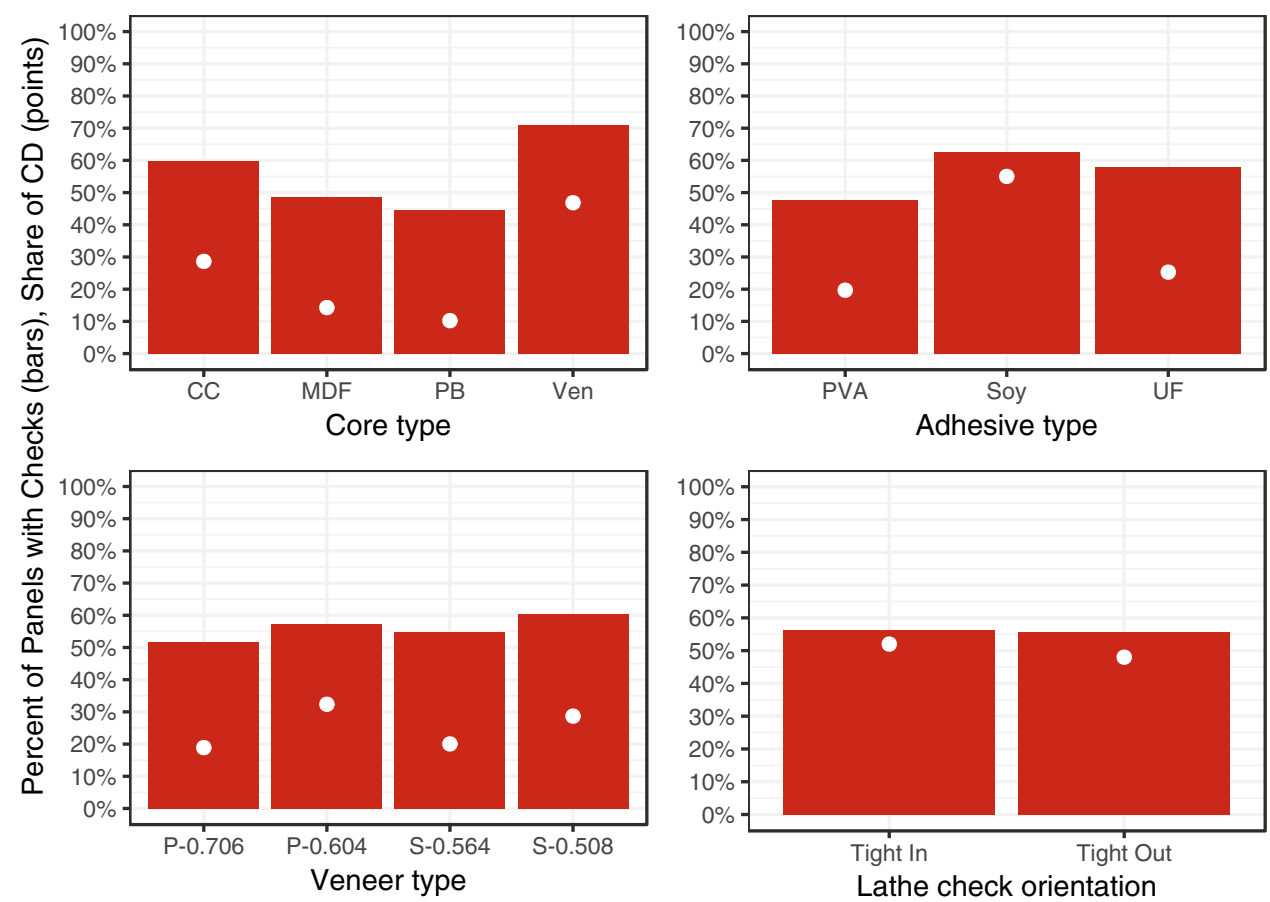

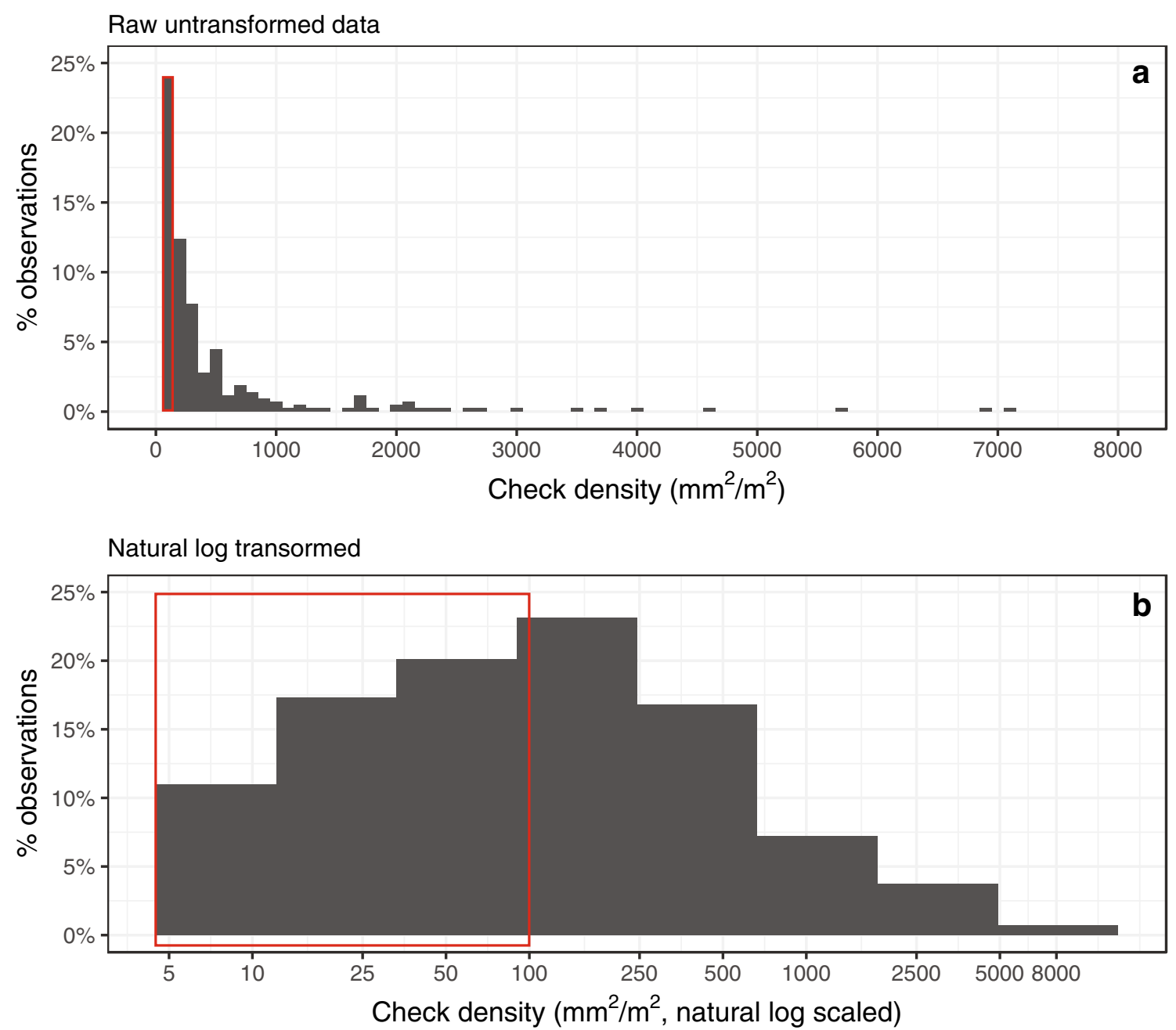

Fig. 2 Histogram of CD on the original scale (a) and the natural $\log$ scale (b) used as the link to the mean in the data model. On the original scale, each bar covers a range of $100 \mathrm{~mm}^{2} / \mathrm{m}^{2}$. On the natural $\log$ scale, each bar covers $\mathrm{e}^{\mathrm{x}}$, where $x$ is an integer between 2 and 9.

the test. The variation in check progression patterns becomes apparent when comparing them between replicate panels for a specific combination of factors, then altering only one factor. For example, Fig. 3 shows the check progression patterns for all panels manufactured using sliced $0.564 \mathrm{~mm}$ veneer, tight-side out lathe check orientation, urea-formaldehyde adhesive, for each of the four core types. The patterns vary between and within core type, and clearly demonstrate the need to consider the point in time at which a checking indicator is recorded. To address this, the maximum observed checking for each panel, the maximum $\mathrm{CD}$, was used as the indicator of checking for comparison.

Examination of the cumulative distribution of $\mathrm{CD}$ by factor level of an individual variable shown in Fig. 4 reveals virtually no difference between factor levels for the adhesive type and lathe check orientation, and only minor differences between various veneer types. The most notable difference is
For example, the first bar is $\mathrm{e}^{2} \mathrm{~mm}^{2} / \mathrm{m}^{2}$ or $\sim 7.4 \mathrm{~mm}^{2} / \mathrm{m}^{2}$ wide, and the fourth bar is $\mathrm{e}^{5} \mathrm{~mm}^{2} / \mathrm{m}^{2}$ or $\sim 148 \mathrm{~mm}^{2} / \mathrm{m}^{2}$ wide. The areas highlighted in red are the same ranges $\left(0-100 \mathrm{~mm}^{2} / \mathrm{m}^{2}\right.$ ) of $\mathrm{CD}$ (color figure online)

between core types. For example, particleboard core panels generally have a higher position on the $y$-axis than veneer core panels, indicating there are fewer particleboard core panels with a given CD than veneer core panels (Fig. 4).

Only one treatment combination (of 96) had no detectable checks in any of the eight replicates; no samples with peeled, $0.706 \mathrm{~mm}$ veneer on particleboard core using soy adhesive with loose-side out face veneer had detectable checks. Only four treatment combinations, all of them with veneer cores, had detectable checks on all replicates (highlighted with bold face in Table 3 ).

Very small check densities (in the first quartile, less than $52 \mathrm{~mm}^{2} / \mathrm{m}^{2}$ ) were observed on panels with 1 or 2 small checks, which may have been as short as $1 \mathrm{~mm}$, and as narrow as $0.2 \mathrm{~mm}$. The longest observed checks were over $100 \mathrm{~mm}$ long and the widest were more than $1 \mathrm{~mm}$ wide. 


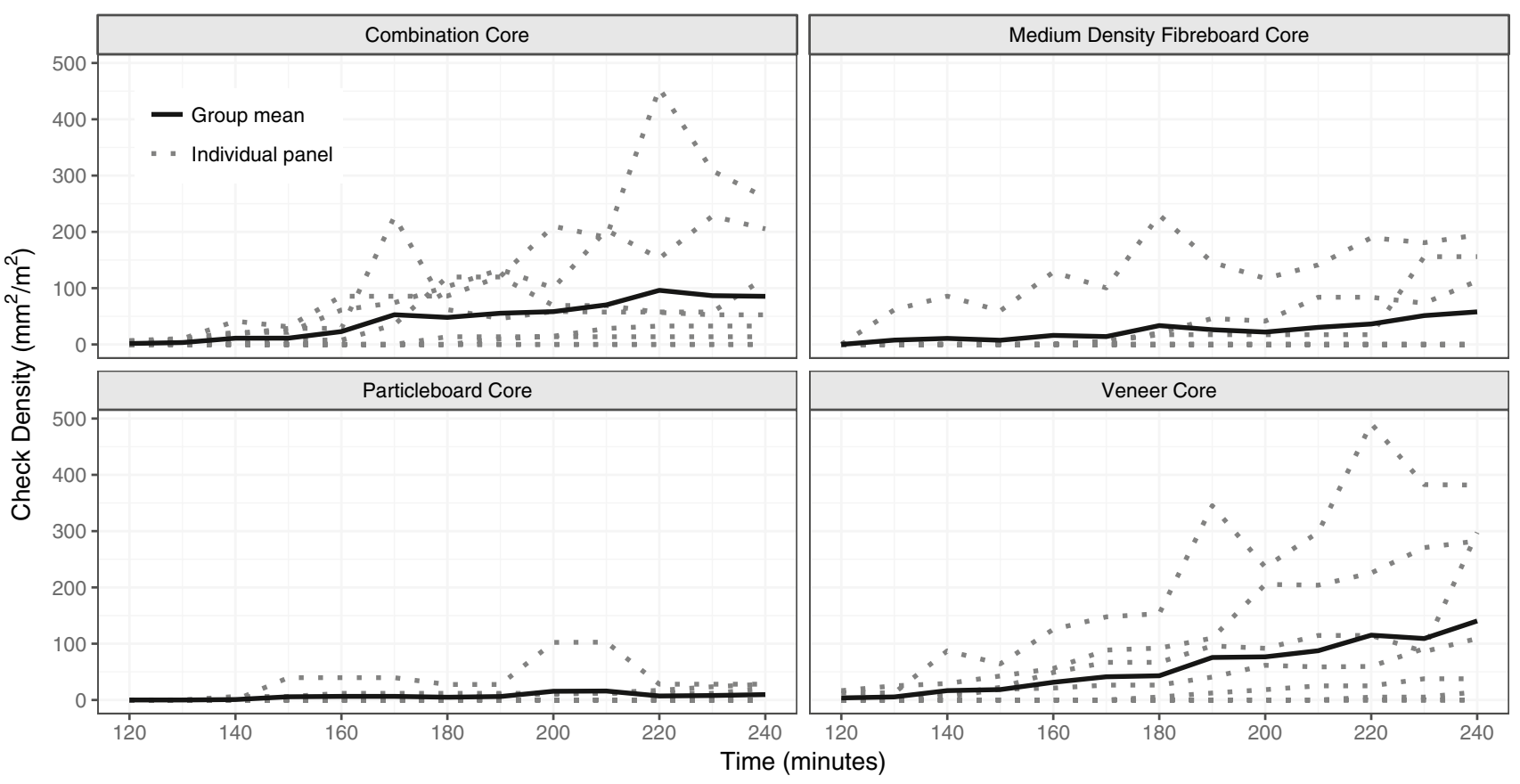

Fig. $3 \mathrm{CD}$ progression for all samples with sliced $0.564 \mathrm{~mm}$ veneer, tight-side out lathe check orientation, urea-formaldehyde adhesive, and each of the core types from the 120th minute through the end of

\subsection{Data model and analysis}

A generalized linear mixed model based on the Tweedie compound Poisson distribution was fitted to the observed check densities using a logarithmic link function. Model fit for generalised linear mixed models is not easily assessed by a single metric (i.e., there is no equivalent of $\mathrm{R}^{2}$ ). However, model results were assessed by comparing estimated values with observations.

Only in two cases, the observed mean $\mathrm{CD}$ fell outside the 95\% confidence interval of the estimated mean. One case was the specimen group that had no observed checking, yet the model produced very small estimated checking values. The second case was for specimens with sliced $0.508 \mathrm{~mm}$ face veneer, veneer core, soy adhesive, and loose-side out lathe check orientation. In this case, the observed mean CD was lower than the lower bound of the $95 \%$ confidence interval of the estimated mean (observed mean CD: $230 \mathrm{~mm}^{2}$ / $\mathrm{m}^{2}$, estimated lower bound: $297 \mathrm{~mm}^{2} / \mathrm{m}^{2}$ ). Other than these isolated incidences, the observed mean $\mathrm{CD}$ fell within the 95\% confidence interval of the estimated mean, indicated the model performed well.

The $\mathrm{CD}$ values estimated by the model for each treatment are presented on the original and natural logarithmic scale in Fig. 5. Again, when the results are shown with natural $\mathrm{CD}$ values on the vertical axis (background chart), the differences between the measured values and the estimated means for individual treatments and between treatments the test period (240th minute). Eight replicates are depicted per plot. Where it appears there are less than 8 individual panel curves in each plot, multiple panels with no checking (zero $\mathrm{CD}$ value) are overlaid

are overwhelmed by the large values at the higher end of the distribution. The superimposed foreground chart shows the same information with $\mathrm{CD}$ values in natural logarithmic scale. The adhesive types are coded with marker shape and the core types with marker colors. Even though the data points represent all four veneer types and lathe check orientations these treatment levels could not be simultaneously visually distinguished without risking confusion. The error bars represent the estimated $95 \%$ confidence intervals for individual treatments. For comparison, the experimental CD values for each treatment are shown as grey square markers.

The model revealed the presence of a four-way interaction between factors (drop in deviance between the full model with all four-way interactions and reduced model with all three-way interactions: drop in deviance $=60, \mathrm{df}=18$, $\mathrm{p}<0.001)$. That is, the effect of any factor depends on the levels of the other factors being used. Therefore, the simple effects of a factor cannot be separated from the effects of other factors. This makes it impractical, and indeed untenable, to offer simple, straightforward recommendations on the use of individual factors (e.g., using a specific adhesive or a specific adhesive with a specific core type). Although checking was observed to be more severe in panels with veneer core, statistical analysis indicated the degree of checking was dependent on a combination of factors that varied by level of the other factors. This observation about treatment combinations may, to some extent, explain the confusion 


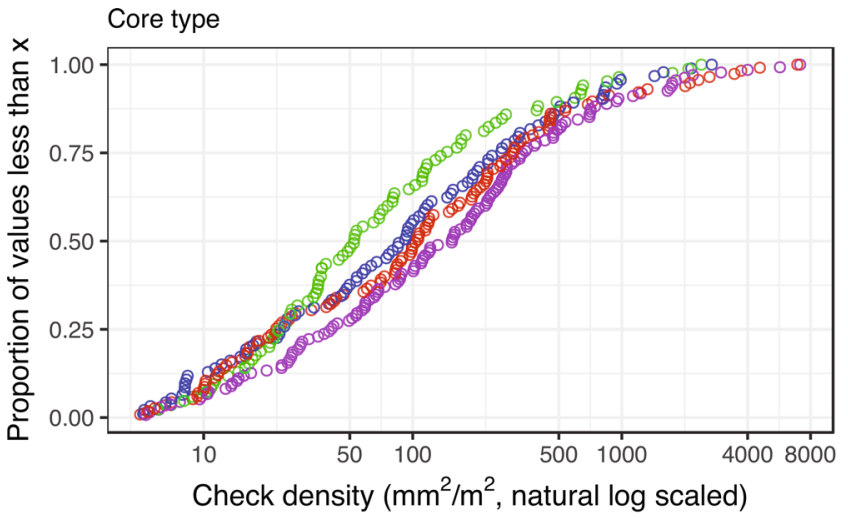

$\circ \mathrm{CC} \circ \mathrm{MDF} \circ \mathrm{PB} \circ \mathrm{Ven}$

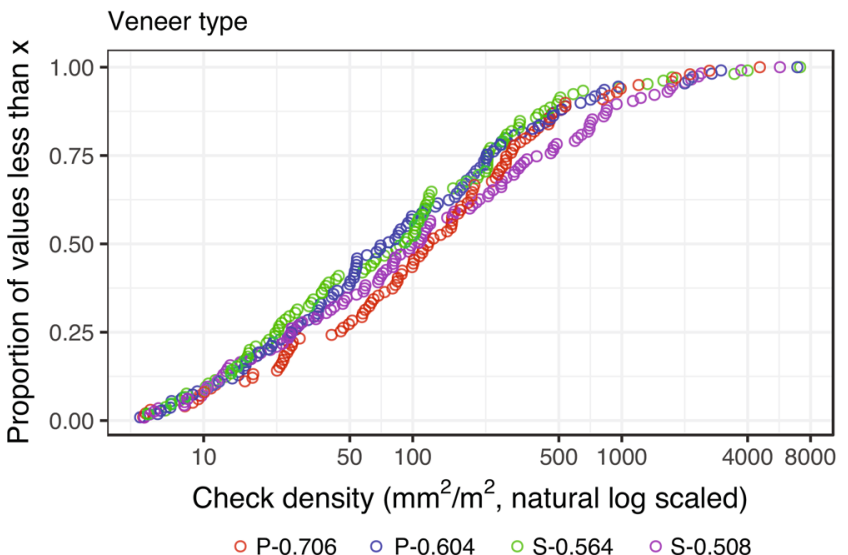

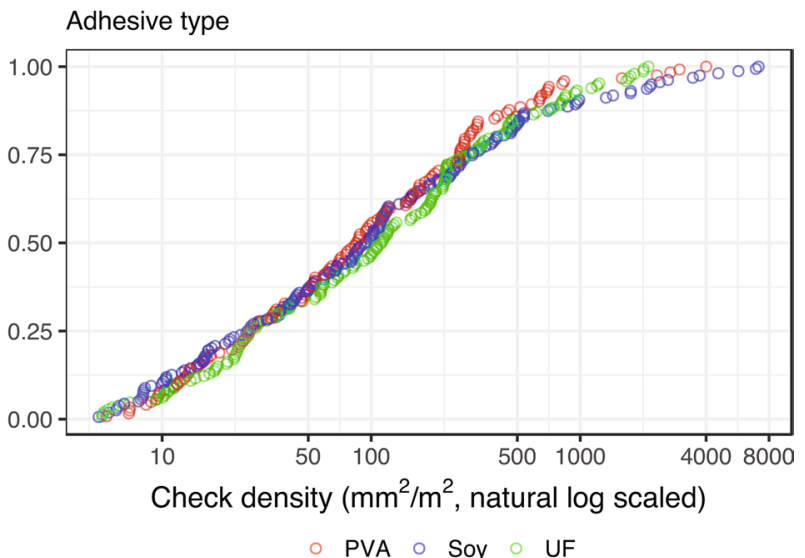

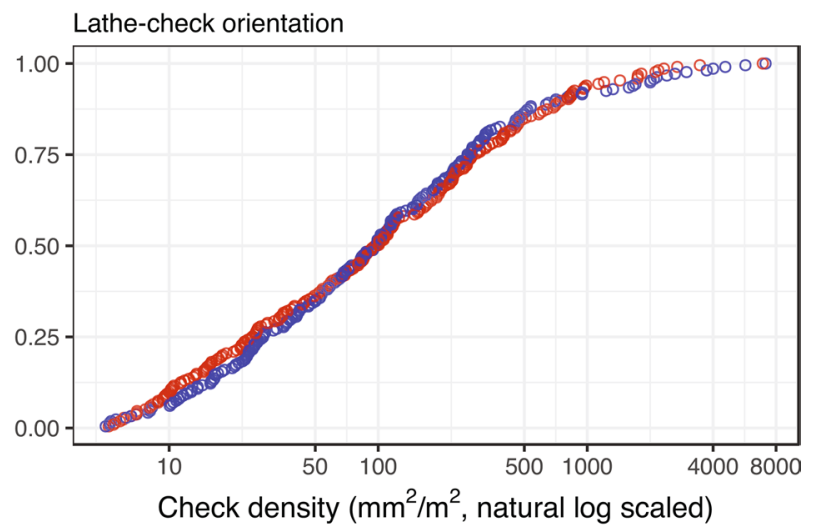

$\circ$ LSO ○ TSO

Fig. 4 Cumulative distributions of observed CD for each factor level grouped by factor. Each chart includes all panels with detected checks ( $n=428$ for each chart). Each point indicates a single replicate

and apparent contradictions in earlier studies examining a limited number of treatments.

Check density is strongly right-skewed, reflecting large variation. The random effect of whole plot only accounted for a small portion of the variance in the data (1.06), and the residual variance was much greater $(17.8$, the dispersion parameter estimated to be equivalent to the residual variance) (Table 4). This indicates other factors not included (e.g., log harvest location and time, log preparation, drying method, other veneer properties, etc.) in the experiment may contribute to check development as well as those in the experiment.

The complexity and variability exposed through the model is best explored in Fig. 5 where the estimated mean $\mathrm{CD}$ for each of the 95 treatments are presented in order of increasing severity. The rank, full description of the treatments, observed mean check density, number of panels with observed checks, as well as the model estimated CDs and associated bootstrapped CIs for each treatment are presented in Table 3.
The estimated mean check densities for the individual treatments range from approximately 0 to $1343 \mathrm{~mm}^{2} / \mathrm{m}^{2}$ (Table 3, Fig. 5).

One practical way of assessing the effect of individual factors used in this study is to examine how the mean $\mathrm{CD}$ values for individual combinations rank among other all other mean $C D$ values, or, in somewhat reduced way, how many panels representing specific variable levels fall in one of the four quartiles of the distribution. The following sections present this information for each of the key factors examined.

\subsection{Effect of veneer}

Panels constructed with all four veneer types have check densities dispersed throughout the entire range of estimated mean check densities. This suggests that the propensity for checks to develop cannot be attributed to veneer preparation method/thickness alone. Estimated mean check densities for panels manufactured with sliced, $0.508 \mathrm{~mm}$ veneer, were 
Table 3 Observed and bootstrapped estimated mean check density with $95 \% \mathrm{BC}_{\mathrm{a}}$ CI's for all treatments; number of panels with detected checks for each treatment combination

\begin{tabular}{|c|c|c|c|c|c|c|c|c|c|}
\hline Rank & Veneer & Lathe checks & Core & Adhesive & Observed mean & $\begin{array}{l}\text { No. panels } \\
\text { with checks }\end{array}$ & $\begin{array}{l}\text { Boot- } \\
\text { strapped } \\
\text { mean }\end{array}$ & $\begin{array}{l}95 \% \text { CI } \\
\text { lower bound }\end{array}$ & $\begin{array}{l}95 \% \text { CI } \\
\text { upper } \\
\text { bound }\end{array}$ \\
\hline 1 & Peeled, 0.706 & LSO & $\mathrm{PB}$ & Soy & 0.000 & 0 & 0 & 0 & 0 \\
\hline 2 & Peeled, 0.604 & TSO & MDF & PVA & 2.903 & 1 & 1.387 & 0 & 6.476 \\
\hline 3 & Peeled, 0.604 & TSO & $\mathrm{MDF}$ & UF & 10.22 & 2 & 6.599 & 0 & 20.41 \\
\hline 4 & Sliced, 0.508 & TSO & $\mathrm{PB}$ & UF & 7.107 & 1 & 6.907 & 0 & 37.92 \\
\hline 5 & Peeled, 0.706 & LSO & MDF & PVA & 14.73 & 1 & 7.038 & 0 & 32.99 \\
\hline 6 & Sliced, 0.564 & LSO & $\mathrm{CC}$ & PVA & 4.553 & 3 & 7.383 & 1.817 & 28.87 \\
\hline 7 & Peeled, 0.604 & LSO & $\mathrm{PB}$ & UF & 8.703 & 1 & 9.208 & 0 & 43.80 \\
\hline 8 & Peeled, 0.604 & LSO & Veneer & PVA & 26.49 & 3 & 14.83 & 0.651 & 83.15 \\
\hline 9 & Peeled, 0.706 & TSO & PB & UF & 15.78 & 4 & 16.16 & 4.225 & 38.26 \\
\hline 10 & Peeled, 0.706 & LSO & PB & PVA & 36.02 & 2 & 18.11 & 0 & 84.90 \\
\hline 11 & Sliced, 0.564 & LSO & PB & UF & 22.27 & 4 & 18.69 & 4.762 & 57.02 \\
\hline 12 & Sliced, 0.564 & TSO & $\mathrm{PB}$ & UF & 18.92 & 3 & 18.76 & 2.845 & 54.11 \\
\hline 13 & Sliced, 0.508 & LSO & $\mathrm{MDF}$ & UF & 34.53 & 2 & 23.40 & 0 & 106.8 \\
\hline 14 & Peeled, 0.706 & TSO & $\mathrm{PB}$ & PVA & 33.41 & 3 & 28.39 & 4.370 & 101.6 \\
\hline 15 & Peeled, 0.604 & LSO & $\mathrm{CC}$ & UF & 34.26 & 5 & 28.74 & 6.237 & 108.0 \\
\hline 16 & Peeled, 0.604 & LSO & PB & PVA & 32.71 & 4 & 35.29 & 13.51 & 96.59 \\
\hline 17 & Peeled, 0.706 & TSO & MDF & PVA & 20.27 & 3 & 36.47 & 5.590 & 136.6 \\
\hline 18 & Sliced, 0.508 & TSO & $\mathrm{MDF}$ & UF & 38.96 & 3 & 38.20 & 2.151 & 130.1 \\
\hline 19 & Peeled, 0.706 & LSO & PB & UF & 58.41 & 3 & 40.76 & 3.185 & 185.0 \\
\hline 20 & Sliced, 0.564 & TSO & $\mathrm{PB}$ & PVA & 83.67 & 2 & 41.64 & 0 & 194.0 \\
\hline 21 & Sliced, 0.508 & TSO & PB & PVA & 57.45 & 4 & 43.14 & 14.70 & 117.6 \\
\hline 22 & Peeled, 0.706 & LSO & $\mathrm{CC}$ & PVA & 24.63 & 3 & 43.71 & 0.798 & 161.0 \\
\hline 23 & Peeled, 0.604 & TSO & $\mathrm{CC}$ & PVA & 53.00 & 3 & 47.73 & 9.339 & 162.6 \\
\hline 24 & Sliced, 0.564 & LSO & $\mathrm{MDF}$ & UF & 48.62 & 5 & 51.67 & 13.20 & 131.7 \\
\hline 25 & Sliced, 0.564 & TSO & MDF & UF & 62.32 & 3 & 53.14 & 8.349 & 142.1 \\
\hline 26 & Sliced, 0.564 & LSO & $\mathrm{MDF}$ & PVA & 86.80 & 3 & 53.27 & 1.329 & 261.0 \\
\hline 27 & Peeled, 0.604 & LSO & PB & Soy & 75.00 & 5 & 53.46 & 14.63 & 162.3 \\
\hline 28 & Sliced, 0.564 & TSO & $\mathrm{CC}$ & PVA & 43.22 & 4 & 53.74 & 11.13 & 183.5 \\
\hline 29 & Sliced, 0.564 & TSO & MDF & Soy & 59.83 & 5 & 53.85 & 8.191 & 233.5 \\
\hline 30 & Peeled, 0.706 & TSO & Veneer & PVA & 47.28 & 3 & 60.36 & 11.35 & 228.0 \\
\hline 31 & Sliced, 0.564 & LSO & $\mathrm{PB}$ & PVA & 42.85 & 4 & 60.41 & 15.99 & 196.9 \\
\hline 32 & Peeled, 0.706 & TSO & MDF & UF & 95.90 & 4 & 64.55 & 8.466 & 187.6 \\
\hline 33 & Peeled, 0.604 & LSO & MDF & Soy & 74.29 & 4 & 67.53 & 12.42 & 233.9 \\
\hline 34 & Peeled, 0.604 & TSO & $\mathrm{PB}$ & PVA & 78.39 & 5 & 67.96 & 11.30 & 305.6 \\
\hline 35 & Sliced, 0.564 & LSO & $\mathrm{CC}$ & UF & 49.12 & 5 & 68.69 & 19.55 & 147.5 \\
\hline 36 & Sliced, 0.508 & TSO & $\mathrm{CC}$ & PVA & 58.69 & 5 & 70.46 & 21.28 & 209.1 \\
\hline 37 & Peeled, 0.604 & TSO & PB & UF & 97.45 & 5 & 72.70 & 20.81 & 149.6 \\
\hline 38 & Peeled, 0.706 & TSO & $\mathrm{CC}$ & UF & 72.12 & 5 & 74.20 & 16.46 & 218.1 \\
\hline 39 & Sliced, 0.508 & LSO & PB & PVA & 103.7 & 6 & 77.91 & 16.57 & 307.8 \\
\hline 40 & Sliced, 0.564 & LSO & Veneer & PVA & 95.03 & 4 & 84.10 & 15.46 & 281.8 \\
\hline 41 & Sliced, 0.564 & TSO & $\mathrm{PB}$ & Soy & 129.7 & 3 & 87.20 & 13.43 & 423.3 \\
\hline 42 & Peeled, 0.706 & LSO & MDF & UF & 38.63 & 4 & 90.92 & 7.095 & 416.8 \\
\hline 43 & Sliced, 0.508 & LSO & $\mathrm{CC}$ & UF & 68.40 & 4 & 96.20 & 4.874 & 284.2 \\
\hline 44 & Peeled, 0.706 & TSO & PB & Soy & 87.05 & 4 & 96.67 & 24.81 & 329.4 \\
\hline 45 & Peeled, 0.706 & LSO & Veneer & PVA & 70.75 & 4 & 106.6 & 25.31 & 369.0 \\
\hline 46 & Peeled, 0.604 & TSO & MDF & Soy & 79.72 & 7 & 110.2 & 44.31 & 275.6 \\
\hline 47 & Sliced, 0.508 & LSO & MDF & Soy & 68.98 & 3 & 116.0 & 2.690 & 658.4 \\
\hline
\end{tabular}


Table 3 (continued)

\begin{tabular}{|c|c|c|c|c|c|c|c|c|c|}
\hline Rank & Veneer & Lathe checks & Core & Adhesive & Observed mean & $\begin{array}{l}\text { No. panels } \\
\text { with checks }\end{array}$ & $\begin{array}{l}\text { Boot- } \\
\text { strapped } \\
\text { mean }\end{array}$ & $\begin{array}{l}95 \% \text { CI } \\
\text { lower bound }\end{array}$ & $\begin{array}{l}95 \% \mathrm{CI} \\
\text { upper } \\
\text { bound }\end{array}$ \\
\hline 48 & Sliced, 0.564 & LSO & Veneer & Soy & 191.1 & 4 & 121.2 & 39.50 & 441.1 \\
\hline 49 & Peeled, 0.604 & TSO & Veneer & Soy & 95.41 & 5 & 125.3 & 34.41 & 365.6 \\
\hline 50 & Sliced, 0.564 & LSO & PB & Soy & 166.6 & 5 & 131.1 & 26.21 & 490.9 \\
\hline 51 & Sliced, 0.508 & TSO & PB & Soy & 303.0 & 2 & 146.4 & 0 & 688.4 \\
\hline 52 & Sliced, 0.508 & LSO & $\mathrm{CC}$ & Soy & 136.8 & 6 & 149.2 & 37.10 & 533.4 \\
\hline 53 & Sliced, 0.564 & TSO & $\mathrm{CC}$ & Soy & 273.0 & 6 & 152.5 & 29.70 & 657.4 \\
\hline 54 & Sliced, 0.564 & TSO & $\mathrm{CC}$ & UF & 203.1 & 6 & 152.6 & 51.07 & 373.7 \\
\hline 55 & Peeled, 0.604 & TSO & PB & Soy & 186.9 & 4 & 152.9 & 6.390 & 875.1 \\
\hline 56 & Sliced, 0.508 & LSO & MDF & PVA & 154.0 & 5 & 154.8 & 28.57 & 540.8 \\
\hline 57 & Peeled, 0.706 & TSO & Veneer & UF & 134.5 & 8 & 154.9 & 71.76 & 313.3 \\
\hline 58 & Peeled, 0.604 & TSO & $\mathrm{CC}$ & UF & 225.0 & 4 & 155.0 & 34.18 & 411.4 \\
\hline 59 & Sliced, 0.564 & TSO & MDF & PVA & 98.66 & 3 & 158.8 & 18.10 & 754.1 \\
\hline 60 & Sliced, 0.508 & LSO & $\mathrm{PB}$ & UF & 218.1 & 4 & 161.5 & 14.03 & 473.5 \\
\hline 61 & Sliced, 0.508 & LSO & Veneer & PVA & 133.5 & 6 & 162.3 & 75.56 & 356.5 \\
\hline 62 & Sliced, 0.564 & TSO & Veneer & UF & 154.7 & 6 & 172.8 & 60.59 & 329.9 \\
\hline 63 & Peeled, 0.604 & TSO & $\mathrm{CC}$ & Soy & 84.91 & 7 & 183.6 & 80.08 & 614.6 \\
\hline 64 & Peeled, 0.604 & LSO & MDF & PVA & 277.3 & 4 & 192.4 & 8.630 & 847.9 \\
\hline 65 & Sliced, 0.508 & TSO & $\mathrm{CC}$ & UF & 357.4 & 5 & 196.8 & 17.46 & 930.7 \\
\hline 66 & Sliced, 0.508 & TSO & $\mathrm{MDF}$ & Soy & 312.2 & 5 & 201.6 & 21.56 & 1015 \\
\hline 67 & Peeled, 0.706 & LSO & $\mathrm{MDF}$ & Soy & 197.4 & 5 & 207.5 & 48.82 & 736.1 \\
\hline 68 & Peeled, 0.604 & LSO & Veneer & Soy & 338.9 & 6 & 210.4 & 15.21 & 1109 \\
\hline 69 & Peeled, 0.706 & LSO & Veneer & Soy & 269.9 & 6 & 215.8 & 46.62 & 884.8 \\
\hline 70 & Peeled, 0.604 & LSO & $\mathrm{CC}$ & PVA & 145.6 & 7 & 224.1 & 101.3 & 450.6 \\
\hline 71 & Sliced, 0.508 & TSO & $\mathrm{MDF}$ & PVA & 160.1 & 7 & 228.6 & 83.01 & 623.6 \\
\hline 72 & Sliced, 0.564 & LSO & $\mathrm{MDF}$ & Soy & 183.6 & 5 & 231.6 & 64.88 & 688.7 \\
\hline 73 & Peeled, 0.706 & TSO & $\mathrm{MDF}$ & Soy & 184.2 & 5 & 240.6 & 46.35 & 971.6 \\
\hline 74 & Peeled, 0.604 & LSO & $\mathrm{MDF}$ & UF & 222.4 & 4 & 250.5 & 60.51 & 685.9 \\
\hline 75 & Sliced, 0.564 & LSO & $\mathrm{CC}$ & Soy & 460.3 & 5 & 252.7 & 11.27 & 1429 \\
\hline 76 & Sliced, 0.508 & TSO & Veneer & PVA & 133.9 & 3 & 258.8 & 66.21 & 932.3 \\
\hline 77 & Peeled, 0.706 & TSO & $\mathrm{CC}$ & PVA & 155.0 & 4 & 268.0 & 104.5 & 787.9 \\
\hline 78 & Sliced, 0.508 & TSO & $\mathrm{CC}$ & Soy & 510.7 & 4 & 292.0 & 12.72 & 1627 \\
\hline 79 & Peeled, 0.706 & LSO & $\mathrm{CC}$ & Soy & 178.8 & 4 & 300.5 & 95.20 & 865.7 \\
\hline 80 & Sliced, 0.564 & LSO & Veneer & UF & 553.3 & 7 & 311.0 & 112.6 & 884.5 \\
\hline 81 & Sliced, 0.564 & TSO & Veneer & PVA & 359.9 & 5 & 314.9 & 18.14 & 1772 \\
\hline 82 & Peeled, 0.706 & TSO & Veneer & Soy & 215.1 & 7 & 349.1 & 155.0 & 861.0 \\
\hline 83 & Peeled, 0.604 & LSO & Veneer & UF & 297.0 & 8 & 374.7 & 159.9 & 750.4 \\
\hline 84 & Peeled, 0.706 & LSO & Veneer & UF & 332.2 & 7 & 382.4 & 119.7 & 1244 \\
\hline 85 & Peeled, 0.706 & LSO & $\mathrm{CC}$ & UF & 498.2 & 5 & 459.2 & 124.7 & 1172 \\
\hline 86 & Sliced, 0.508 & LSO & $\mathrm{PB}$ & Soy & 368.1 & 7 & 481.1 & 172.7 & 1300 \\
\hline 87 & Sliced, 0.508 & LSO & $\mathrm{CC}$ & PVA & 442.8 & 4 & 506.1 & 116.1 & 1740 \\
\hline 88 & Sliced, 0.564 & TSO & Veneer & Soy & 935.5 & 5 & 509.2 & 21.18 & 2294 \\
\hline 89 & Peeled, 0.604 & TSO & Veneer & UF & 354.7 & 6 & 540.2 & 132.7 & 1771 \\
\hline 90 & Sliced, 0.508 & LSO & Veneer & Soy & 230.4 & 8 & 564.6 & 297.4 & 1625 \\
\hline 91 & Sliced, 0.508 & LSO & Veneer & UF & 415.6 & 6 & 594.5 & 238.1 & 1182 \\
\hline 92 & Peeled, 0.604 & TSO & Veneer & PVA & 548.8 & 4 & 748.9 & 216.7 & 2362 \\
\hline 93 & Sliced, 0.508 & TSO & Veneer & UF & 769.9 & 8 & 784.4 & 336.9 & 1363 \\
\hline 94 & Peeled, 0.706 & TSO & $\mathrm{CC}$ & Soy & 1005 & 5 & 908.9 & 158.7 & 2858 \\
\hline 95 & Peeled, 0.604 & LSO & $\mathrm{CC}$ & Soy & 990.1 & 6 & 1236 & 115.0 & 4947 \\
\hline
\end{tabular}


Table 3 (continued)

\begin{tabular}{llllllllll}
\hline Rank & Veneer & Lathe checks & Core & Adhesive & Observed mean & $\begin{array}{l}\text { No. panels } \\
\text { with checks }\end{array}$ & $\begin{array}{l}\text { Boot- } \\
\text { strapped } \\
\text { mean }\end{array}$ & $\begin{array}{l}\text { 95\% CI } \\
\text { lower bound }\end{array}$ & $\begin{array}{l}\text { 95\% CI } \\
\text { upper } \\
\text { bound }\end{array}$ \\
\hline 96 & Sliced, 0.508 & TSO & Veneer & Soy & 816.2 & 7 & 1343 & 232.6 & 6242 \\
\hline
\end{tabular}

$L S O$ loose-side out; TSO tight-side out, $C C$ combination core, $P B$ particleboard, $M D F$ medium density fibreboard, $P V A$ polyvinyl acetate, $U F$ urea formaldehyde

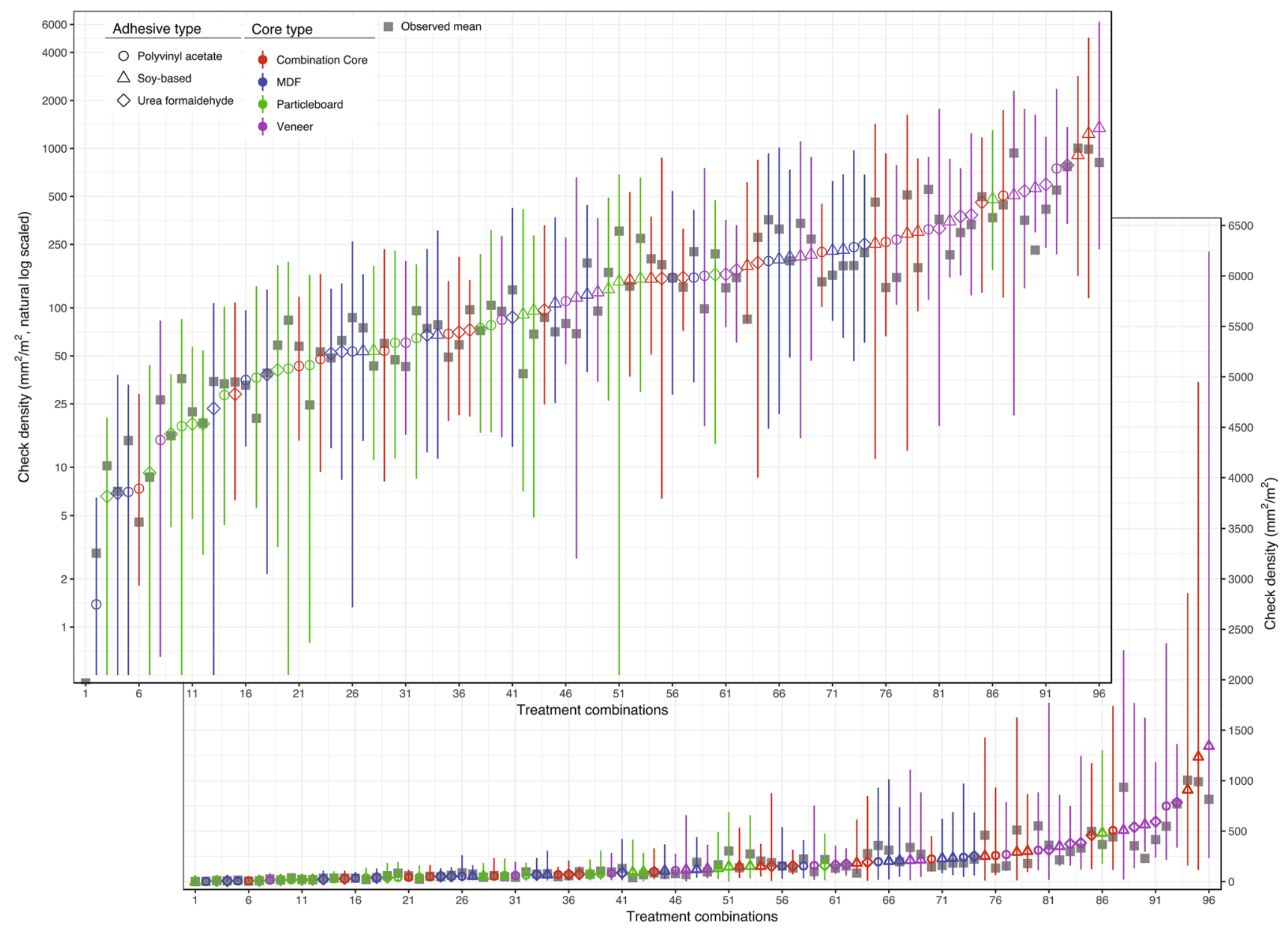

Fig. 5 Observed and estimated $\mathrm{CD}$ means with $95 \% \mathrm{BC}_{\mathrm{a}}$ confidence intervals by treatment ordered from least to greatest. The top panel is on a natural log scale, and the bottom panel is on the raw scale. Esti-

Table 4 Parameters from the Tweedie compound Poisson model fit to the observed data and the values extracted from the bootstrap, with 95\% BC $\mathrm{a}$ CI's

\begin{tabular}{lccl}
\hline Parameter & Data model & Bootstrap value & Bootstrap 95\% CI \\
\hline $\begin{array}{l}\text { Index } \\
\begin{array}{l}\text { Dispersion/ } \\
\text { residual vari- }\end{array}\end{array}$ & 17.58 & 1.58 & $1.58-1.60$ \\
$\begin{array}{l}\text { ance } \\
\text { Whole plot }\end{array}$ & 1.09 & 17.2 & $16.2-20.3$ \\
\hline
\end{tabular}

mated means and confidence intervals are bootstrapped. 1 treatment is removed from the natural log scale panel to simplify display (the treatment ranked 1)

highest, with $66 \%$ of estimated check means falling into the 3rd and 4th quartiles, or above $121 \mathrm{~mm}^{2} / \mathrm{m}^{2}$ (Table 5, Fig. 5).

\subsection{Effect of lathe check orientation}

Panels constructed with both lathe check orientations (tightside out and lose-side out) have mean check densities distributed throughout the full range of estimated check densities (Fig. 5, Table 6). The observed data and resulting model 
provide no evidence that lathe check orientation alone contributes to check development in maple veneered decorative panels. These observations contradict the conclusions of previous studies that lathe check orientation effect can be isolated from other complex interactions (Cassens et al. 2003; Leavengood et al. 2011). The authors` model suggests lathe check orientation is entangled in 4-way interactions with other variables, and therefore, based on their data, it cannot be concluded that one lathe check orientation will lead to greater probability or degree of checking than the other. It is important to note that the characteristics and quantity of any pre-existing cracks were not studied here, only the lathecheck orientation of the face veneer at the time of assembly.

\subsection{Effect of core material}

Panels with veneer core tended to have high estimated mean check densities (54\% of estimated CDs fall in the 4th quartile). Panels with particleboard core tended to have low estimated mean check densities, indicating they performed the best in terms of checking (50\% of estimated CDs fall in the 1st quartile) (Table 7, Fig. 5). The high check densities for panels with veneer cores is likely attributable to the fact that these panels were produced with the face veneer grain orientation parallel to the grain orientation of the veneer core. However, recent research in which the face veneer was oriented perpendicular to the grain orientation of the veneer core also confirms that there is a greater tendency for checking on veneer core material (Wilson 2018).

Based on this analysis, in panels with checks, the decorative plywood panels with particleboard cores seemed to mitigate the amount of checking.

\subsection{Effect of adhesive type}

The range of estimated mean CD separated by the adhesive type (Table 8 ) shows interesting trends. While $66 \%$ of estimated mean CD values for PVA bonded panels and $56 \%$ of the UF bonded panels fall into the two lower quartiles (i.e., are likely to check at CD levels below $121 \mathrm{~mm}^{2} / \mathrm{m}^{2}$ ), $72 \%$ of panels bonded with soy adhesive fall in the two higher quartiles of estimated mean CD (i.e., above $121 \mathrm{~mm}^{2} / \mathrm{m}^{2}$ ),
Table 5 Percent of panels of each type falling into quartiles of all estimated means by veneer type
Table 6 Percent of panels of each type falling into quartiles of all estimated means by lathe check orientation

\begin{tabular}{lllll}
\hline Veneer type & Quartile & & \\
\cline { 2 - 5 } & $\begin{array}{l}1 \mathrm{st} \\
(\mathrm{CD}<52 \\
\left.\mathrm{mm}^{2} / \mathrm{m}^{2}\right)(\%)\end{array}$ & $\begin{array}{l}2 \mathrm{nd} \\
(\mathrm{CD} \leq 121\end{array}$ & $\begin{array}{l}3 \mathrm{rd} \\
(\mathrm{CD} \leq 232\end{array}$ & $\begin{array}{l}\text { 4th } \\
(\mathrm{CD} \leq 1343\end{array}$ \\
& 33 & 25 & $\left.\mathrm{~mm}^{2} / \mathrm{m}^{2}\right)(\%)$ & $\left.\mathrm{m}^{2}\right)(\%)$ \\
\hline Peeled, $0.706 \mathrm{~mm}$ & 21 & 13 & 29 \\
Peeled, $0.604 \mathrm{~mm}$ & 29 & 38 & 29 & 21 \\
Sliced, $0.564 \mathrm{~mm}$ & 21 & 17 & 25 & 17 \\
Sliced, $0.508 \mathrm{~mm}$ & 17 & 33 & 33 \\
\hline
\end{tabular}

\begin{tabular}{|c|c|c|c|c|}
\hline \multirow{2}{*}{$\begin{array}{l}\text { Lathe check } \\
\text { orientation }\end{array}$} & \multicolumn{4}{|l|}{ Quartiles } \\
\hline & $\begin{array}{l}1 \mathrm{st} \\
(\mathrm{CD}<52 \\
\left.\mathrm{mm}^{2} / \mathrm{m}^{2}\right)(\%)\end{array}$ & $\begin{array}{l}2 \mathrm{nd} \\
(\mathrm{CD} \leq 121 \\
\left.\mathrm{mm}^{2} / \mathrm{m}^{2}\right)(\%)\end{array}$ & $\begin{array}{l}3 \mathrm{rd} \\
(\mathrm{CD} \leq 232 \\
\left.\mathrm{mm}^{2} / \mathrm{m}^{2}\right)(\%)\end{array}$ & $\begin{array}{l}\text { 4th } \\
(\mathrm{CD} \leq 1343 \\
\left.\mathrm{mm}^{2} / \mathrm{m}^{2}\right)(\%)\end{array}$ \\
\hline $\begin{array}{l}\text { Tight-side } \\
\text { out }\end{array}$ & 27 & 25 & 23 & 25 \\
\hline $\begin{array}{l}\text { Loose-side } \\
\text { out }\end{array}$ & 23 & 25 & 27 & 25 \\
\hline
\end{tabular}

Table 7 Percent of panels of each type falling into quartiles of all estimated means by core type

\begin{tabular}{lllll}
\hline Core type & Quartiles & & & \\
\cline { 2 - 5 } & $\begin{array}{l}1 \mathrm{st} \\
(\mathrm{CD}<52\end{array}$ & $\begin{array}{l}2 \text { nd } \\
(\mathrm{CD} \leq 121\end{array}$ & $\begin{array}{l}3 \mathrm{rd} \\
(\mathrm{CD} \leq 232\end{array}$ & $\begin{array}{l}\text { 4th } \\
(\mathrm{CD} \leq 1343\end{array}$ \\
& $\left.\mathrm{mm}^{2} / \mathrm{m}^{2}\right)(\%)$ & $\left.\mathrm{mm}^{2} / \mathrm{m}^{2}\right)(\%)$ & $\left.\mathrm{mm}^{2} / \mathrm{m}^{2}\right)(\%)$ & $\left.\mathrm{mm}^{2} / \mathrm{m}^{2}\right)(\%)$ \\
\hline Combination core & 17 & 21 & 29 & 33 \\
MDF & 29 & 33 & 29 & 8 \\
Particleboard & 50 & 29 & 17 & 4 \\
Veneer & 4 & 17 & 25 & 54 \\
\hline
\end{tabular}


Table 8 Percent of panels of each type falling into quartiles of all estimated means by adhesive type

\begin{tabular}{lllll}
\hline Adhesive type & \multicolumn{3}{l}{ Quartiles } & \\
\cline { 2 - 5 } & $\begin{array}{l}1 \mathrm{st} \\
(\mathrm{CD}<52 \\
\left.\mathrm{mm}^{2} / \mathrm{m}^{2}\right)(\%)\end{array}$ & $\begin{array}{l}2 \mathrm{nd} \\
(\mathrm{CD} \leq 121 \\
\left.\mathrm{mm}^{2} / \mathrm{m}^{2}\right)(\%)\end{array}$ & $\begin{array}{l}3 \mathrm{rd} \\
(\mathrm{CD} \leq 232 \\
\left.\mathrm{mm}^{2} / \mathrm{m}^{2}\right)(\%)\end{array}$ & $\begin{array}{l}\text { 4th } \\
(\mathrm{CD} \leq 1343 \\
\left.\mathrm{mm}^{2} / \mathrm{m}^{2}\right)(\%)\end{array}$ \\
\hline Polyvinyl acetate & 38 & 28 & 19 & 16 \\
Soy & 3 & 25 & 38 & 34 \\
Urea formaldehyde & 34 & 22 & 19 & 25 \\
\hline
\end{tabular}

with $33 \%$ likely to check above $232 \mathrm{~mm}^{2} / \mathrm{m}^{2}$ (i.e., in the $4^{\text {th }}$ quartile).

Figures 6 and 7 show the estimated mean CD for all combinations sorted by the core material: particleboard (Fig. 6a), MDF (Fig. 6b), combination (Fig. 7a), and veneer core (Fig. 7b), respectively. In these charts, the adhesive and core types are coded by marker shape and colour, respectively, and lathe orientation is indicated by the type of the error bar line (solid line for loose side out, dashed line for tight side out). These charts may be of some practical use for manufacturers to weigh decisions regarding panel lay-up, if they have selected a particular type of core material. The results of this study can be used in a similar way for assessing the levels of other factors examined, or for any combination of them. The relatively small differences between some combinations indicate only minor gains or losses when selecting specific manufacturing variables.

\section{Discussion}

Customer complaints related to checking are more likely when the severity of checking increases, and there is no standard definition of an acceptable amount of checking. Therefore, examining the range of estimated check densities from the model provides the most straightforward insight into which treatments are more or less likely to perform well in case of occasional severe drying exposures.

As in prior research (Cassens et al. 2003; Leavengood et al. 2011), the results suggest significant interactions among factors. The complexity of the interactions should prompt caution in attributing checking propensity in decorative maple plywood to any single factor of panel construction. For example, a manufacturer should not decide to change adhesive types to avoid check formation without considering the concurrent effects of other factors.

While entangled four-way interactions are not easy to interpret, the reduced data and charts parsed by selected variables generated by the model may be a useful tool for estimating the propensity of selected combinations for checking at severe drying exposure events.

Manufacturers may consider Table 3 or Figs. 5, 6, 7, which present the ordered mean check densities and provide an index of increasing risk of a claim. The variability associated with the estimates, as represented by $95 \%$ confidence intervals, indicate that check development in decorative maple veneer panels may be related to factors beyond those included in this study. That is, the examined factors do not provide a complete understanding of check development. No factor or factor level can easily be dismissed from consideration either.

It should be stressed that this study has not addressed all possible factors, which may and should be explored in future studies. Examples include the moisture content of the core and veneer components at the time of pressing, log/flitch conditioning method, veneer source region and harvest season, veneer drying method, etc. In addition, the variability inherent within panel components (i.e., veneers, adhesives, cores) is likely to contribute to the degree of checking as well. Accordingly, in future research the test methodology used in this study should be employed to investigate the variability within panel components and the effects of other factors discussed in the rich literature of the subject in order to confirm or dismiss earlier hypotheses. Currently, the bottleneck of the method seems to be the fabrication of test specimens in lab environment.

\section{Conclusion}

An innovative optical method was successfully used for investigation of the impact of four decorative plywood panel manufacturing factors (core type, veneer type, adhesive type and lathe check orientation) commonly believed to affect face veneer checking. This method allowed automated examination of a large number of panels and measurement of detailed checking information as checking occurred. One particular advantage of this method was that it allowed detecting the peak check densities as they occurred in panels at different times of exposure. That in turn allowed for meaningful comparisons of check densities not possible when surfaces are examined at an arbitrary point in time. In $56 \%$ of panels with detectable checks, peak CDs occurred before the end of the 240-min testing period.

Checks were detected on $56 \%$ of all inspected specimens. Only one treatment-peeled $0.706 \mathrm{~mm}$ veneer on 

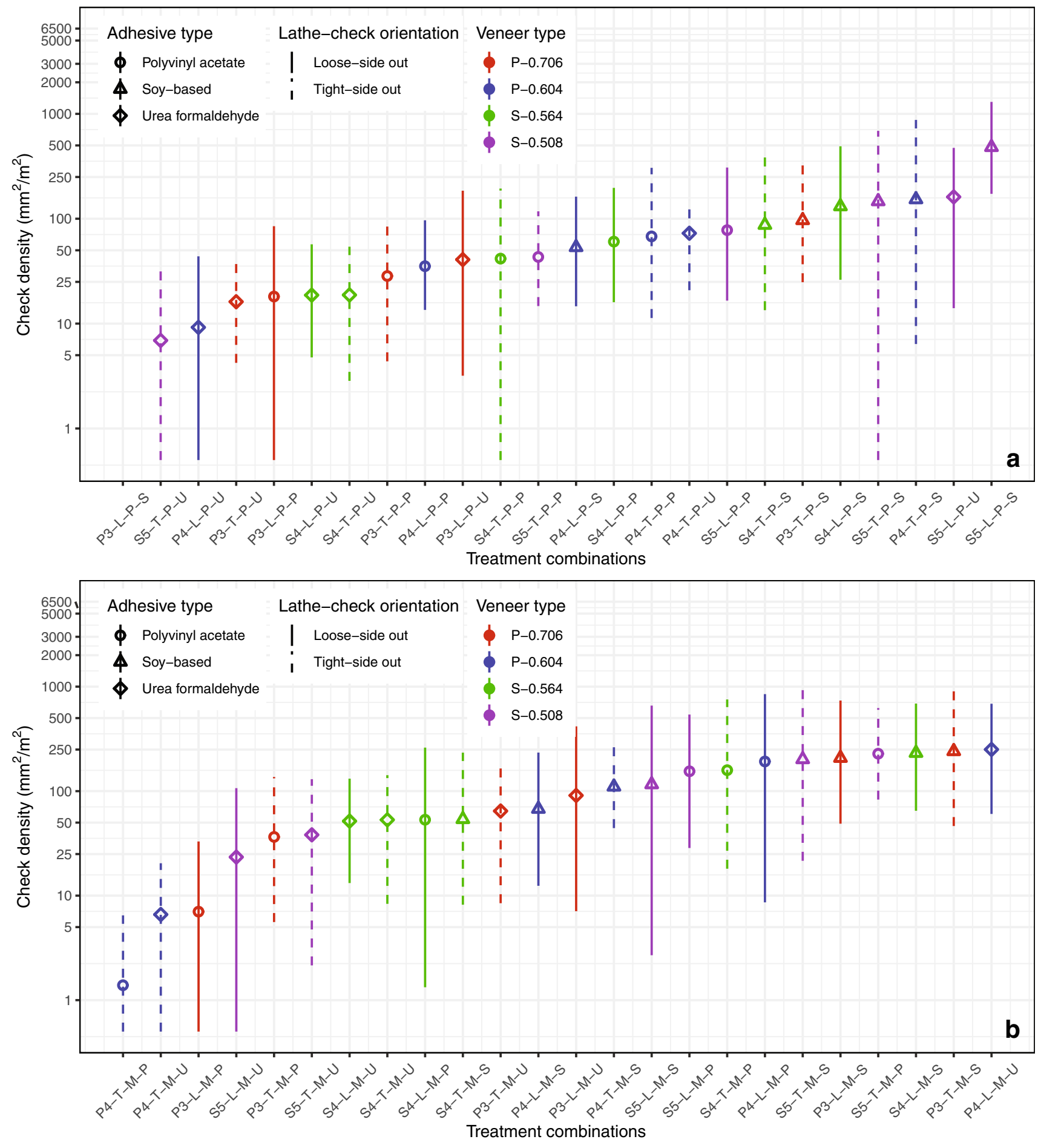

Fig. 6 Estimated $\mathrm{CD}$ means with $95 \% \mathrm{BC}_{\mathrm{a}}$ confidence intervals for all panels made with particleboard core (a) and MDF core (b), and all other manufacturing factors noted. $\mathrm{X}$-axis label key: indicator order is: Veneer type-Lathe check orientation-Core type-Adhe-

particleboard core using soy-based adhesive with the lathe checks oriented out (loose side out) — had no detectable checks on any of the eight replicates examined. In only four sive type. Values are: $\mathrm{P} 3=$ peeled, $0.706 \mathrm{~mm}, \mathrm{P} 4=$ peeled, 0.604 , $\mathrm{S} 4=$ sliced, $0.564, \mathrm{~S} 5=$ sliced $0.508 ; \mathrm{L}=$ loose-side out, $\mathrm{T}=$ tight side out; $\mathrm{P}=$ particleboard; $\mathrm{M}=\mathrm{MDF}, \mathrm{P}=$ polyvinyl acetate, $\mathrm{S}=$ soybased, $\mathrm{U}=$ urea formaldehyde

treatment, checks were detected in all 8 of the replicates investigated. The complexity of the checking process and the number of variables that may affect it make generalisations 

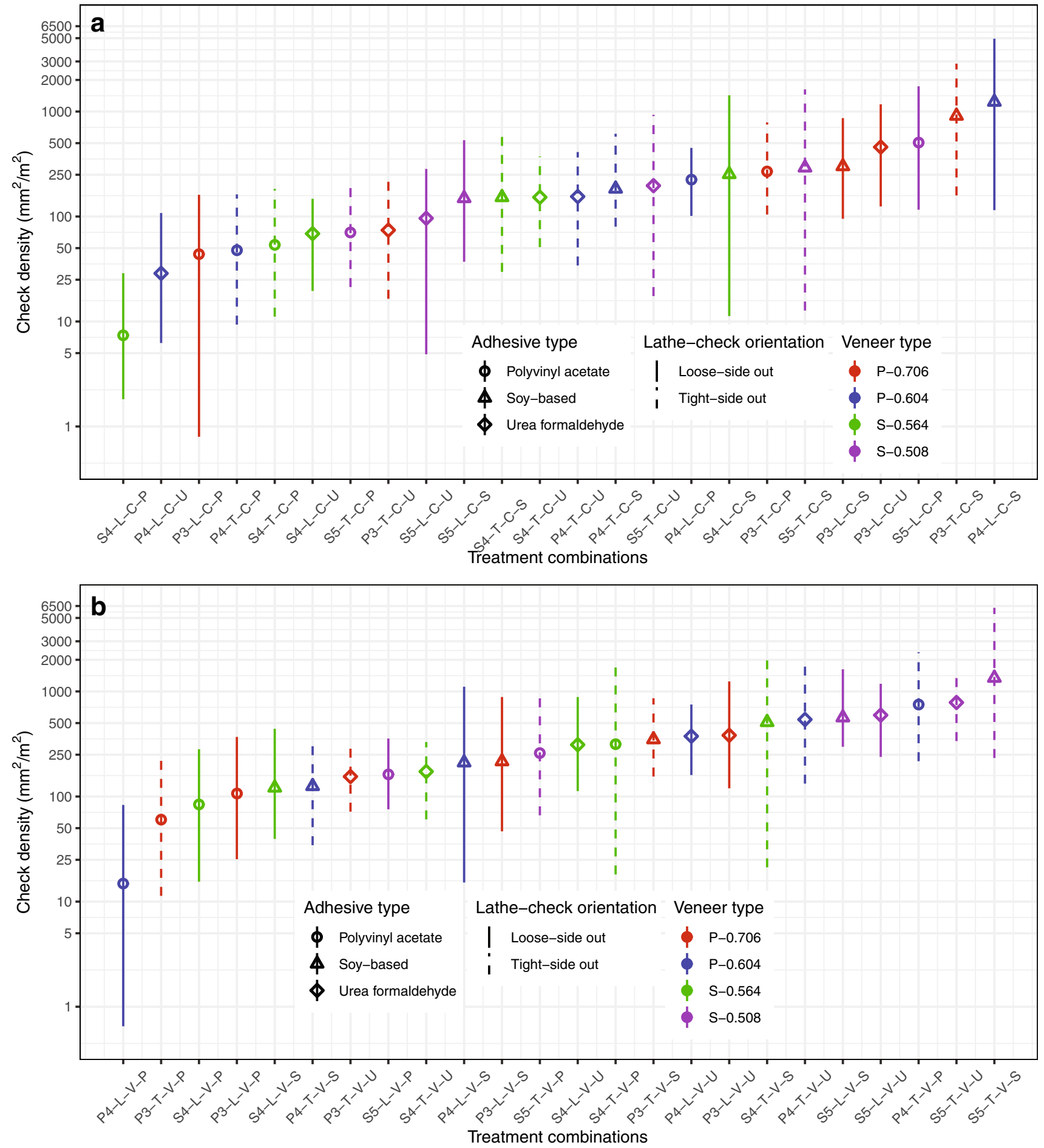

Fig. 7 Estimated $\mathrm{CD}$ means with $95 \% \mathrm{BC}_{\mathrm{a}}$ confidence intervals for all panels made with combination core (a) and veneer core (b), and all other manufacturing factors noted. X-axis label key: indicator order is: Veneer type-Lathe check orientation-Core type-Adhe-

beyond the specific materials and processes represented by the 96 combinations of factors studied here difficult to support. However, the most generalizable conclusion may sive type. Values are: $\mathrm{P} 3=$ peeled, $0.706 \mathrm{~mm}, \mathrm{P} 4=$ peeled, 0.604 , $\mathrm{S} 4=$ sliced, $0.564, \mathrm{~S} 5=$ sliced $0.508 ; \mathrm{L}=$ loose-side out, $\mathrm{T}=$ tight side out; $\mathrm{C}=$ combination core; $\mathrm{V}=$ veneer core; $\mathrm{P}=$ polyvinyl acetate, $\mathrm{S}=$ soy-based, $\mathrm{U}=$ urea formaldehyde

be that conventional wisdom related to the best lathe check orientation to reduce checking, and indeed previous research results, cannot be supported by the evidence in this study. 
This suggests that check development may be more directly related to the characteristics and quantity of pre-existing cracks in the veneer than can be attributed only to the lathecheck orientation of the veneer in the assembled panel. The presence of checks and the observed check densities were nearly equal between lathe check orientations.

The model used to estimate the probability of high level of check densities in products with specific manufacturing options is charged with substantial uncertainties. At the current stage, practitioners should use it with caution. However, the tools used here for exploring and comparing check densities do allow isolation of the most suitable panel types within individual manufacturer's constraints.

The test method used in this study allows larger and more comprehensive investigations as well as a more accurate way to detect and measure check intensity at any time throughout the checking process. In future research this method should be employed to investigate the effects of other factors discussed in the rich literature of the subject in order to confirm or dismiss earlier hypotheses. This check characterisation methodology, particularly in combination with rapid veneer characterisation methods such as those demonstrated in Rohumaa et al. (2018) and other useful assessment methodologies can help shed light on a greater range of potential check development factors, especially those related to the characterisation and quantification of pre-existing cracks which are hypothesised to contribute to the degree of checking in the final panel.

A qualitative study examining the extent of checking (number, size, visibility) acceptable to end users may be helpful to provide manufacturers with some indicator of the tolerance end users have regarding checking.

Acknowledgements This project was funded by the USDA Special Grant program for Wood Utilization Research with generous contributions from the members of the Western Hardwood Plywood Producers-Columbia Forest Products, Murphy Plywood, Roseburg Forest Products, States Industries, and Timber Products Company. Special thanks are extended to Professor Mihael Perman for his helpful advice about the bootstrapping technique, and to Aleksandar Tošić for providing computational time. Michael Burnard gratefully acknowledges the European Commission for funding the InnoRenew CoE project (Grant Agreement \#739574) under the Horizon2020 Widespread-Teaming program.

\section{Compliance with ethical standards}

Conflict of interest On behalf of all authors, the corresponding author states that there is no conflict of interest.

Open Access This article is distributed under the terms of the Creative Commons Attribution 4.0 International License (http://creativeco mmons.org/licenses/by/4.0/), which permits unrestricted use, distribution, and reproduction in any medium, provided you give appropriate credit to the original author(s) and the source, provide a link to the Creative Commons license, and indicate if changes were made.

\section{References}

Auguie B (2016) gridExtra: Miscellaneous functions for "grid" graphics. R package version 2.2.1. https://CRAN.R-project.org/packa ge $=$ gridExtra

Batey TEJ (1955) Minimizing face checking of plywood. Forest Prod J 5(10):277-285

Buchelt B, Wagenführ A, Dietzel A, Raßbach H (2018) Quantification of cracks and cross-section weakening in sliced veneers. Eur J Wood Prod 76(1):381-384. https://doi.org/10.1007/s0010 7-017-1238-Z

Burnard M (2012) Key factors influencing checking in maple veneered decorative hardwood plywood. Oregon State University. Corvallis, OR, USA. Master's Thesis

Burnard M, Ganio L (2019) Inspecting, plotting, and modelling check density in decorative maple veneered plywood panels. Figshare. https://doi.org/10.6084/m9.figshare.6964862.v1. Accessed 30 Aug 2019

Burnard M, Muszyński L, Leavengood S, Ganio L (2018) Investigating face veneer check development in decorative plywood panels: An optical method for detecting and measuring check severity. Eur J Wood Prod 76(5):1367-1377. https://doi.org/10.1007/s0010 7-018-1327-7

Canty A, Ripley B (2019) boot: Bootstrap R (S-Plus) functions. R package version 1.3-23

Cassens D, Leng Y, McCabe G (2003) Face check development in veneered furniture panels. For Prod J 53(10):79-86

Christiansen AW, Knaebe M (2004) Diagnostic guide for evaluating surface distortions in veneered furniture and cabinetry. Technical Report. US Forest Service Forest Products Laboratory, Madison

Davidson AC, Kuonen D (2003) An introduction to the bootstrap with application in R. Stat Comput Stat Graph Newsl 13:6-11

Davison, AC, Hinkley, DV (1997) Bootstrap methods and their application, vol 1. Cambridge University Press, Cambridge. ISBN $0-521-57391-2$

Diciccio TJ, Efron B (1996) Bootstrap confidence intervals. Stat Sci 11(3):189-212. http://www.jstor.org/stable/2246110

Efron B (1984) Better bootstrap confidence intervals. Stanford University, Palo Alto. http://www.dtic.mil/dtic/tr/fulltext/u2/a150798.pdf

Efron B, Tibshirani R (1986) Bootstrap methods for standard errors, confidence intervals, and other measures of statistical accuracy. Stat Sci 1:54-77

Feihl O, Godin V (1970) Peeling defects in veneer, their causes and control. Canadian Forestry Services, Ottowa

Forbes CL (1997) Understanding and minimizing veneer checking on furniture panels. North Carolina State University, Raleigh

Gilmore RC, Hanover SJ (1990) Suggestions for preventing or minimizing veneer checking. North Carolina State University, Raleigh

Glass S, Zelinka S (2010) Wood handbook, Chapter 04: Moisture relations and physical properties of wood. General Technical Report FPL-GTR-190. Madison, WI: U.S. Department of Agriculture, Forest Service, Forest Products Laboratory: 4-1-4-19. Chapter 4

Haukoos JS, Lewis RJ (2005) Advanced statistics: Bootstrapping confidence intervals for statistics with "difficult" distributions. Acad Emerg Med 12:360-365. https://doi.org/10.1197/j. aem.2004.11.018

Holcombe RA (1952) Surface checking in furniture panels. J For Prod Res Soc 2(5):122-127

HPVA (2011) Hardwood plywood and veneer association, Email correspondence between S. Leavengood and K. Howlett

HPVA (2018) Hardwood plywood and veneer association, Email correspondence between S. Leavengood and K. Howlett

Kang H-Y, Muszynski L, Milota MR (2006) Optical measurement of non-uniform drying strains and drying check formation in 
refractory species. In: Proceedings of FPS conference on quality drying for the 21st century, Bellingham, pp 15-17

Kang H-Y, Muszyński L, Milota M, Kang C, Matsumura J (2011) Preliminary tests for optically measuring drying strains and check formation in wood. J Fac Agric Kyushu Univ 56(2):313-316

Leavengood S, Funck JW, Reeb EW (2011) A note on face veneer checking in maple plywood. Int Wood Prod J 2(2):120-123

GOM, mbH (2004) Aramis version 5.4.3. [Software application] Braunschweig, Germany: GOM, mbH

Rohumaa A, Viguier J, Girardon S, Krebs M, Denaud L (2018) Lathe check development and properties: effect of log soaking temperature, compression rate, cutting radius and cutting speed during peeling process of European Beech (Fagus Sylvatica L.) Veneer. Eur J Wood Prod 76(6):1653-1661. https://doi.org/10.1007/s0010 7-018-1341-9

Schramm A (2003) A complete guide to hardwood plywood and face veneer. Purdue University Press, West Lafayette

Stark NM, Zhiyong C, Caril CG (2010) Wood handbook, Chapter 11: wood-based composite materials-panel products- glued-laminated timber, structural composite lumber, and wood-nonwood composite materials. General Technical Report FPL-GTR-190. Madison, WI: U.S. Department of Agriculture, Forest Service, Forest Products Laboratory: 11-1-11-28. Chapter 11

R Core Team 2017. R: A language and environment for statistical computing. R Foundation for Statistical Computing, Vienna, Austria. https://www.R-project.org/

Tremblay C, Bouffard JF (2012) Study on the Issue of Veneer Cracking in the Kitchen Cabinet and Furniture Industry. FPInnovations. http://www.valuetowood.ca/html/english/research_development/ area_projects_details.php?prj_id=165. Accessed 29 Jan 2014

Wickham H (2009) ggplot2: elegant graphics for data analysis. Springer, New York, p 2009

Wickham H (2016) scales: Scale functions for visualization. R package version 0.4.1. https://CRAN.R-project.org/package $=$ scales

Wickham H (2017) tidyr: Easily Tidy Data with 'spread()' and 'gather()' Functions. R package version 0.6.1. https://CRAN.Rproject.org/package $=$ tidyr

Wickham H, Francois R (2016) dplyr: a grammar of data manipulation. R package version 0.5.0. https://CRAN.R-project.org/packa $\mathrm{ge}=\mathrm{dplyr}$

Wilson EJ (2018) Check characterization in maple plywood. Oregon State University. Corvallis, OR, USA. Master's Thesis. Online: https://ir.library.oregonstate.edu/downloads/8w32rb58x. Accessed 11 June 2018

Zhang Y (2013) Likelihood-based and Bayesian methods for Tweedie compound Poisson Linear mixed models. Stat Comput 23(6):743-757

Zhang Y (2017) cplm: Compound poisson linear models. R package version 0.7 .5

Publisher's Note Springer Nature remains neutral with regard to jurisdictional claims in published maps and institutional affiliations. 